II.

\title{
Bericht iiber die von der schwedischen Aerzte- gesellschaft veranstaltete Sammelforschung über die Krebskrankheit in Schweden während der Zeit rom 1. Dezember 1905 bis 28. Februar 1906.
}

Erstattet von dem Krebsforschungskomitee der Gesellschaft.

(Hierzu Tafel I-III.)

\section{Arbeitsplan.}

In Veranlassung eines am 16. Mai 1905 an die schwedische Aerztegesellschaft eingereichten Schreibens, unterzeichnet von den Mitgliedern der Gesellschaft, den Herren John Berg, Otto Sandberg, S. E. Henschen, J. G. Edgren, C. Sundberg, P. J. Wising, J. Akerman, Fr. Westermark, M. Salin und E. G. Johnson, einen Vorschlag zur Ausführung einer Sammelforschung über die Krebskrankheit in Schweden enthaltend, beschloss die Aerztegesellschaft am 6. Juni 1905 eine solche Sammelforschung $\mathrm{zu}$ veranstalten und beauftragte ein Komitee, aus den Mitgliedern der Gesellschaft, Herren J. Berg, E. O. Hultgren, O. Sandberg, C. Sundberg und Fr. Westermark bestehend, die Anordnung und Ausführung der Forschungsarbeit zu besorgen und über dieselbe einen gedruckten Bericht abzustatten. Am 14. September 1905 hatte das Komitee seine koustituierende Sitzung, wobei zum Vorsitzenden Herr Prof. J. Berg und zum Sekretär Herr Dr. 0. Sandberg gewählt wurden. Nachdem Herr C. Sundberg im März 1906 den Wunsch ausgesprochen, seines Auftrages enthoben zu werden, wählte die Gesellschaft an seiner Stelle Herrn G. Hedrén.

Da die Aerztegesellschaft sich ausserstande sah, aus eigenen Mitteln sämtliche durch das Ausführen der Arbeit bedingte Kosten zu bestreiten, hat die Königl. Schwedische Regierung, auf untertäniges Ersuchen der Gesellschaft, am 13. Oktober 1905 den Betrag von 2500 Kronen für diesen Zweck zur Verfügung gestellt. 
Um die grösstmögliche Beteiligung der Aerzte zu erreichen, hat sich die Aerztegesellschaft die gefällige Mitwirkung des Königl. Medizinalamtes auserweten. In einem Schreiben an die Aerztegesellschaft sprach auch das Königl. Medizinalamt sein lebhaftes Interesse für die in Frage gesetzte Sammelforsehung aus und forderte das Komitee dazu auf, bei dem Medizinalamte Erkundigungen einzuziehen über die Formen, unter welchen das Medizinalamt bereit sein könnte, bei der Durchführung der Sammelforschung mitzuwirken.

Nachdem das Komitee einen Entwurf zum Frageblatt ausgearbeitet hatte und derselbe von dem Medizinalamt genehmigt worden war, erliess das Medizinalamt an sämtliche praktische Aerzte des Reiches das unten wiedergegebene Rundschreiben, wobei dem Komitee gestattet wurde, dem genannten Schreiben teils das Frageblatt des Komitees, teils ein ron den Mitgliedern unterzeichnetes, kollegiales Schreiben beizufügen.

Wortlaut des Zirkularschreibens des Königl. Medizinalamtes:

\section{$\mathrm{Zirku} 1$ a r}

an sämtliche praktizierende Aerzte des Reiches mit Einforderung gewisser Angaben in betreff der Krebskrankheit.

Nachdem die schwedische Aerztegesellschaft sich bereit erklärt, eine für die Krankbeitsverhältnisse unseres Landes in hohem Masse bedeutsame Untersuchung über die Aetiologie der Krebskrankheit usw. auszuführen, und die Regierung durch gnädigen Erlass vom 13. Oktober d. J. für diesen Zweck Nittel zur Verfügung gestellt hat, ersucht Sie hiermit das Königl. Medizinalamt, auf Ersuchen der Gesellschaft und mit Stütze der $\S \S 5$ und 21 der für das Amt geltenden gnädigen Instrultion, vor dem 15. März 1906 das beigefügte Frageblatt auszufüllen und einzusenden, und soll dasselbe dann der Gesellschaft zweeks Ausführung obengenannter Untersuchung übergeben werden.

Stockholm, den 3. November 1905.

$$
\text { Klas Linroth. }
$$

Anton Holmberg.

Das Rundschreiben des Komitees und das Frageblatt hatten nachstehenden Wortlaut:

\section{Herr Kollege!}

Zwecks Ermittelung der Frequenz und Ausbreitung der Krebskrankheiten sind in mehreren Ländern, wie Deutschland, Holland, England, Frankreich, Spanien, Portugal, Ungarn und Griechenland, von ärztlicher Seite Sammelforschungen angestellt worden, wobei sämtliche an einem gewissen Tage vorkommende Fälle verzeichnet worden sind. 
Die schwedische Aerztegesellschaft ist der Ansicht, dass unser Land auf diesem internationalen Arbeitsfeld nicht vermisst werden darf, und hat deshalb am 6. Juni 1905 beschlossen, ein Komitee zu wählen mit dem Auftrage, innerhalb Schwedens die Anordnung und Durchführung einer derartigen Untersuchung zu besorgen. Die Zahl der Mitglieder dieses Komitees ist auf 5 festgesetzt worden, und sind die Unterzeichneten zu Mitgliedern erwählt worden. Nach Erachten des Komitees ist eine Zeit von mindestens 3 Monaten erforderlich zum Aufbringen genügenden Materials für eine befriedigende Beantwortung der obengenannten Frage. Dieser Zeitraum ist auch von dem Königl. Medizinalamte, an das sich das Komitee, laut Beschluss der Gesellschaft, gewandt hat, genehmigt worden. Die Untersuchung beginnt am 1. Dezember 1905 und dauert bis zum 28. Februar 1906.

Für jeden Krebsfall, der während der gesagten Zeit in Ihre Behandlung kommt, ist ein Frageblatt auszufüllen. Alle Frageblätter, benutzte wie unbenutzte, sind an das Komitee vor dem 15. März 1906 einzusenden. Falls Sie während dieser Zeit keinen Krebsfall in Ihrer Behandlung gehabt haben, ist dies bei dem Einsenden der Frageblätter besonders anzugeben.

Fälle, wo die klinische Untersuchung nur zur Diagnose maligner Tumor geführt hat, sind auch in den Frageblättern, mit Angabe der genannten Diagnose, aufzuführen.

Auch unzweifelhafte Fälle von Sarkom sind aufzuführen, wobei selbstverständlich diese Diagnose anzugeben ist, damit neben der eigentlichen Krebssammelforschung Aufklärungen auch über die Frequenz des Sarkoms zu gewinnen sind.

Obgleich durch die in Frage stehende Untersuchung grosse Ansprüche an Ihre schon sonst streng in Anspruch genommene Zeit. gestellt werden, hofft doch das Komitee auf das Mitwirken eines jeden schwedischen Arztes an dieser wichtigen Arbeit rechnen zu dürfen.

Stockholm, den 1. November 1905.

John Berg, Vorsitzender.
E. O. Hultgren.
C. Sundberg.
Fr. Westermark.
Otto Sandberg, Sekretär. 
Das Krebsforschungskomitee der schwedischen Aerztegesellschaft. Stockholm.

Konfidentiell.
Sämtliche ausgefüllte wie auch alle unbenutzten Frageblätter sind vor dem 15. März 1906 unter nebenstehender Adresse einzusenden. Dorthin sind auch alle Anfragen sowie die Requisition von weiteren Frageblättern zu adressieren.

\section{Frage blatt}

über Krebskranke in Schweden warnend der Zeit vom 1. Dezember 1905 bis 28. Februar $1906^{1}$ ).

1. Vollständiger Vor- und Familiennamen ${ }^{2}$ )

2. Alter: ............ Jahre. 3. Mann, Weib - verheiratet, ledig, geschieden Witwer, Witwe. 4. Beruf oder Beschäftigung.

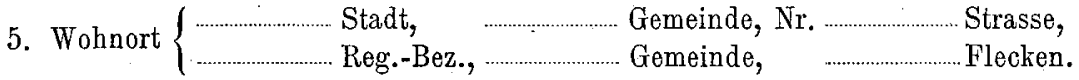
Wenn anzunehmen ist, dass die Krankheit an anderem Orte entstanden ist, ist dieser anzugeben

6. Wann sind, Ihres Erachtens, die ersten Krankheitserscheinungen wahrscheinlich aufgetreten ${ }^{?}$ )

7. Worauf gründen Sie die Diagnose in diesem Falle?

Falls mikroskopische Diagnose gestellt worden, ist diese anzugeben.

8. Welches Organ ist, Ihres Erachtens, zuerst befallen worden?

9. Welche Organe sind später befallen worden?

10. Falls Operation stattgefunden, in welchem Krankenhaus?... Wann?

11. Ist der Kranke gestorben?. An welchem Tage?

Falls Sektion vorgenommen, ist die wesentliche pathologisch-anatomische Diagnose anzugeben

12. Findet sich Krebs bei Vater, Mutter, Geschwistern, Kindern, sonstigen Verwandten, Gatten, Gattin und in welchem Organe?

13. Ist in diesem Falle, Jhres Erachtens, eine Ansteckung anzunehmen? Aus welchen Gründen?.

1) Falls der Arzt während der Forschungszeit keinen Krebsfall ị seiner Behandlung gehabt hat, ist dies, mitsamt der Namensunterschrift, auf dem. Frageblatt anzugeben.

2) Für besondere Ausnahmefälle kann der Familiennamen lediglich durch den Anfangsbuchstaben angegeben werden.

3) Bei interessanten Fällen werden ausführlichere Krankengeschichten in besonderer Beilage mit Dankbarkeit entgegengenommen. 
14. Finden sich in der Anamnese irgend welche bemerkenswerte a) vorausgegangene Krankheiten (Alkoholismus, Arterioskierose, Gicht, Syphilis, Tuberkulose usw.)?

b) lokale Prozesse (Ulcus ventriculi, Gallensteine, chronische Endometritis, Lupus, alte Unterschenkelgeschwüre, Narben nach Verbrennungen, Trauma usw.)?

c) sonstige Umstände (Tabakmissbrauch, ungesunde Wohnungen, schlechtes Trinkwasser, ungeeignete Nahrung, schädliche Einwirkung gewisser Berufe, zahlreiche Entbindungen, Aborte usw.)?

d) Familienkrankheiten (Arthritis deformans, Gicht, Diabetes, Fettsucht, Epilepsie, Geisteskrankheiten usw.)?

15. Hat der Kranke während der Forschungszeit andere Aerzte zu Rate gezogen, welche?

\section{approbierter Arzt.}

Bei einer Untersuchung wie der vorliegenden ist es zwar von grosser Bedeutung, dass die Zeit der Sammelforschung eine verhältnismässig lange Periode umfasst, andererseits ist aber auch die in der Regel streng in Anspruch genommene Zeit der mitwirkenden Aerzte zu berücksichtigen. Durch die in obigem Frageblatt festgesetzte Zeit von 3 Monaten dürften diese beiden Gesichtspunkte in bestmöglicher Weise zufriedengestellt worden sein.

In bereits genannter Weise wurden die Frageblätter des Komitees an 1331 im Reiche praktizierende Aerzte versandt; 1295 (97,3 pCt.) Aerzte sandten die ihnen zugegangenen Frageblätter zurück; 649 (50,1 pCt.) dieser Aerzte machten die Mitteilung, dass sie während der für die Sammelforschung festgesetzten Zeit keine Krebs- oder Sarkomfälle in Behandlung gehabt hätten. Es dürfte einzig dastehend sein, dass Aerzte so zahlreich an einer Sammelforschung teilgenommen haben.

Da die Möglichkeit nicht vòn der Hand zu weisen ist, dass ein und derselbe Fall von verschiedenen Aerzten gemeldet werden könnte, die jeder den fraglichen Kranken in Bebandlung gehabt, hat der Statistiker des Komitees aus den Antworten auf die Fragen 1, 2, 5 und 15 des Frageblattes näher untersucht, ob dem so gewesen, wobei es sich herausgestellt hat, dass sich 160 Fälle finden, die vou mehr als einem Arzte ge- 
meldet worden sind. Selbstverständlich hat das Komitee in bezug auf diese Fälle die nötige Korrektur vorgenommen. Ausserdem sind einige wenige Fälle wegen unvollständiger oder schwebender Angaben abgesondert worden.

Das Material, das nach der aus verschiedenen Gründien vorgenommenen Sichtung übrig blieb, bestand aus 1754 Krebsfällen and 118 Sarkomfällen, und es ist dieses Material, das der von dem Komitee, laut dem erteilten Auftrage, bewerkstelligten Bearbeitung zugrunde liegt.

Die rein statistische Bearbeitung ist von dem Aktuar im Königl, statiștischen Zentralbureau, Dr. phil. Edv. Arosenius ausgeführt worden.

In dem Frageblatt sind mehrere Fragen zur Beantwortung aufgenommen worden, die später bei der nachfolgenden Bearbeitung des Materials nicht zur Behandlung kamen. Dies hat darin seinen Grund, dass die fraglichen Antworten sich einer wissenschaftlichen Bearbeitung nicht haben unterziehen lassen.

\section{Die Verbreitnng des Krebses in Schweden.}

In nachstehender Tabelle A finden sich die Krebskranken, nach den verschiedenen Regierungsbezirken geordnet, auf Land und Städte, sowie auf die beiden Geschlechter verteilt. Der Ort, wo der Kranke bei dem ersten Erscheinen der Krankheit ansässig gewesen ist, also in der Regel der Wohnort, ist der geographischen Verteilung zugrunde gelegt worden ${ }^{1}$ ); wo aber der Arzt einen anderen Ort als den Wohnort bei dem ersten Auftreten der Krankheit angegeben hat, was in beinahe 100 Fällen geschehen ist, ist der Fall zn diesem. Orte gezählt worden. Nur in bezug auf einige wenige Krebskranke, die sich bei dem ersten Erscheinen der Krankheitssymptome im Auslande aufhielten, ist die Ausnahme gemacht worden, dass sie bei ihrem Wohnorte im Reich aufgeführt worden sind. Im übrigen ist $\mathbf{z u}$ bemerken, dass die Gemeinde Lundby, welche wäbrend der Forschungszeit mit der Stadt Göteborg inkorporiert wurde, dieser letzteren zugezäblt worden ist.

In betreff der Krebsfrequenz, d. h. der Zahl der Krebskranken auf 100000 Einwohner, ist die Berechnung nur für jeden Regierungsbezirk, ohne Unterschied zwischen Land und Stadt, ausgeführt worden.

Die Krebsfrequenz betreffend, ist im übrigen zu bemerken, dass die absolute Zahl, welche der Berechnung zugrunde liegt, die Zahl der während der Sammelforschungszeit angetroffenen Krebsfälle ist, was im folgenden

1) In dieser Beziehung unterscheidet sich unsere Untersuchung von einigen ähnlichen ausländischen, wo die geographische Verteilung nach dem Wohnort des Arztes gemacht worden ist. 
überall gilt, wo von der Krebsfrequenz die Rede ist. Die Frequenzziffer gibt also nicht die Krebsmorbidität während eines Jahres an.

Tabelle A. Die Krebskranken nach dem Wohnorte.

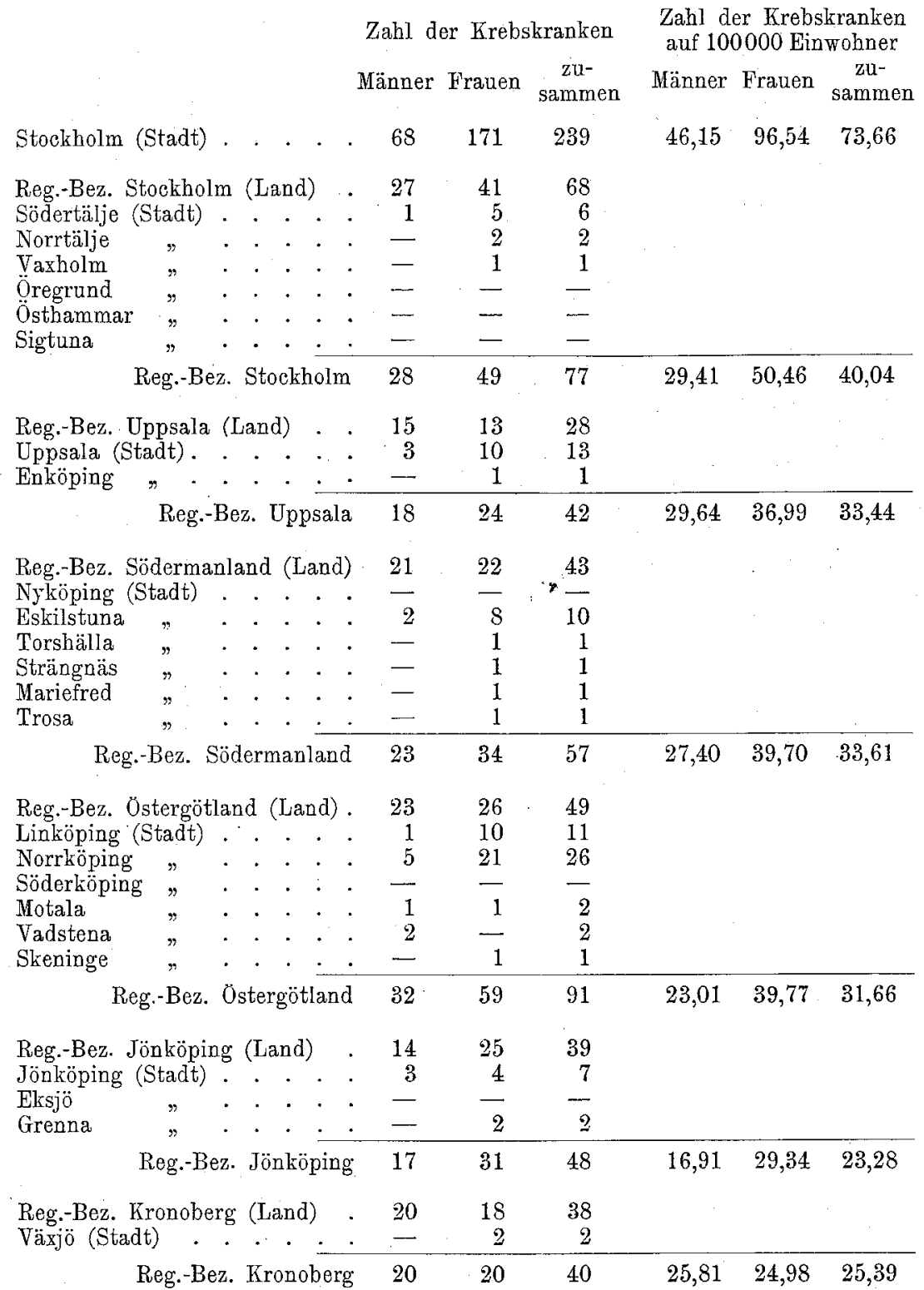


Zahl der Krebskranken

Männer Frauen cu-
Zahl der Krebskranken auf 100000 Einw ohner

Mönner Frauen zusammen

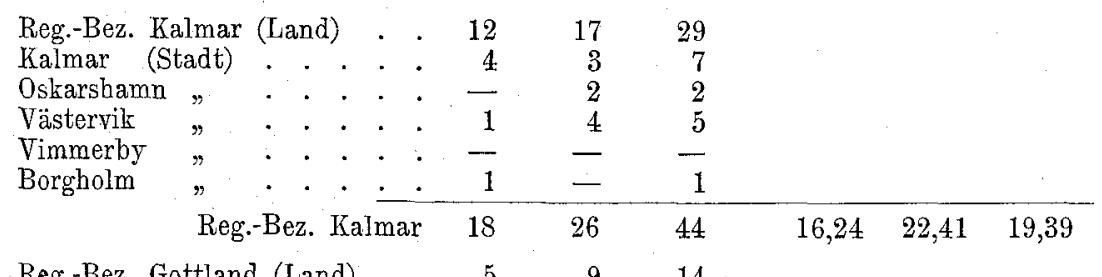

-Reg.-Bez. Gottland (Land) . . $\quad \begin{array}{llll}5 & 9 & 14\end{array}$

Visby (Stadt)

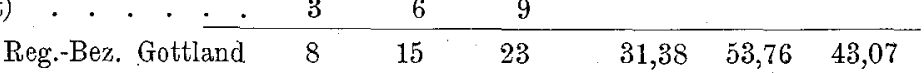

Reg.-Bez. Blekinge (Land) . . $17 \quad 13 \quad 30$

Karlskrona (Stadt) . . . . . . . $\quad 4 \quad 4 \quad 6 \quad 60$

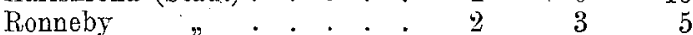

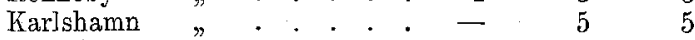

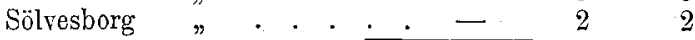

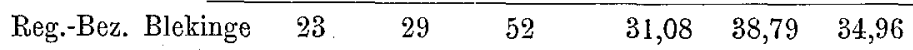

Reg.-Bez. Kristianstad (Land) . $22 \quad 28 \quad 50$

Kristianstad (Stadt) . . . . 1 - 1

Simrishamn $\quad$. . . . . $\quad-11$

$\begin{array}{llllllllll}\text { Ängelholm } & \# & . & \text {. } & . & . & 1 & 2 & 3\end{array}$

$\begin{array}{lllllll}\text { Reg.-Bez. Kristianstad } & 24 & 31 & 55 & 22,35 & 27,50 & 24,99\end{array}$

Reg.-Bez. Malmöhus (Land) . . $33 \quad 37 \quad 37 \quad 70$

$\begin{array}{lllll}\text { Malmö (Stadt) . . } & 11 & 23 & 34\end{array}$

Lund $\quad \ldots \quad$. . - - $7 \begin{array}{r}7 \\ 7\end{array}$

$\begin{array}{lllllll}\text { Landskrona } & \cdots & . & . & 1 & 2 & 3\end{array}$

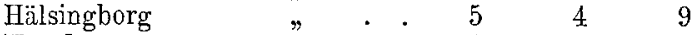

$\begin{array}{lllllll}\text { Ystad } & \cdots & . & 1 & 2 & 3\end{array}$

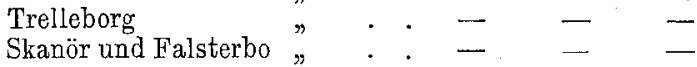

$\begin{array}{lllllll}\text { Reg.-Bez. Malmöhus } & 51 & 75 & 126 & 24,30 & 33,92 & 29,24\end{array}$

Reg.-Bez. Halland (Land) . . . $\quad \begin{array}{cccc} & 9 & 14 & -23\end{array}$

Halmstad (Stadt) . . . . . . . $\begin{array}{ccccc} & 1 & 6 & 7\end{array}$

Laholm

$\begin{array}{llllllllll}\text { Laholm } & " & \cdot & \cdot & \cdot & \cdot & \cdot & - & - & - \\ \text { Falkenberg } & \# & \cdot & : & \cdot & \cdot & \cdot & - & - & - \\ \text { Varberg } & " & . & . & \cdot & : & \cdot & 1 & 2 & 3\end{array}$

Kungsbacka ,

$\begin{array}{lllllll}\text { Reg.-Bez. Halland } & 11 & 22 & 33 & 15,85 & 29,72 & 23,00\end{array}$

Reg.-Bez. Göteborg und Bohus

(Land) . . . . . . . . . . $26 \quad 33 \quad 59$

Göteborg (Stadt) . . . . . . $\quad \begin{array}{llll} & 50 & 64 & 114\end{array}$

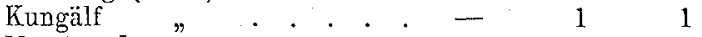

Marstrand " $\quad . \quad . \quad . \quad . \quad . \quad-\frac{1}{1} \quad-1$

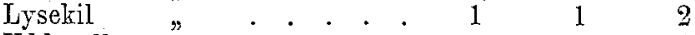

Uddevalla . . . . . . . . . .

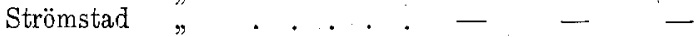

$\begin{array}{lllllll}\text { Reg.-Bez. Göteborg und Bohus } & 77 & 103 & 180 & 44,90 & 55,49 & 50,40\end{array}$ 
Zahl der Krebskranken

Männer Frauen
Zahl der Krebshranken auf 100000 Einwohner

zu- Mäner Frauen zusammen Männer Frauen sammen

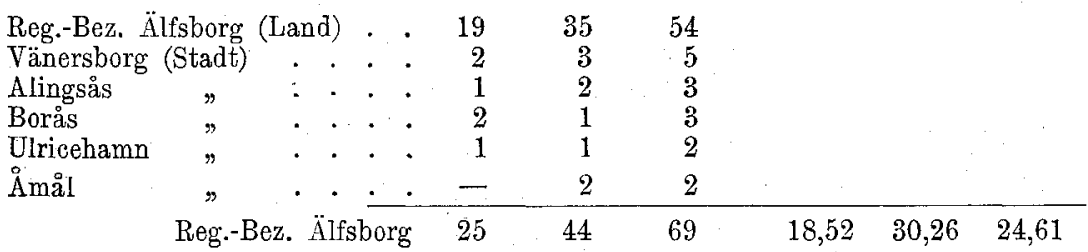

Reg.-Bez. Skaraborg (Land) . $21 \quad 15.36$

Mariestad (Stadt) . . . . . $\quad-\quad 11$

Lidköping " $\quad . \quad . \quad . \quad . \quad . \quad \begin{array}{rrr}- & - & -\end{array}$

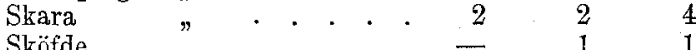

Sköfde $\quad " \quad \cdot \quad \cdot \quad \cdot \quad \cdot \quad \cdot \quad-\quad \begin{array}{lll}1 & 1\end{array}$

Hjo

Falköping

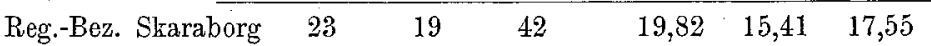

Reg.-Bez. Värmland (Land) . $31 \quad 33 \quad 74$

$\begin{array}{llllll}\text { Karlstad (Stadt). . . . . . } & 3 & 7 & 10\end{array}$

Kristinehamn " . . . . . . 11304

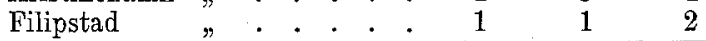

$\begin{array}{llllllll}\text { Reg.-Bez. Värmland } & 36 & 54 & 90 & 29,04 & 41,17 & 35,27\end{array}$

Reg.-Bez. Örebro (Land) . . $21 \quad 29 \quad 50$

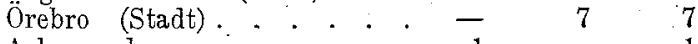

Askersund " . . . . . . . . . $11 \quad 1 \quad-1$

\begin{tabular}{llllllllllllll} 
Nora & $\#$ & $\cdot$ & $\cdot$ & $\cdot$ & $\cdot$ & $\cdot$ & $\cdot$ & - & - & $\overline{2}$ & & \\
Lindesberg & $\cdots$ & $\cdot$ & $\cdot$ & $\cdot$ & $\cdot$ & $\cdot$ & $\cdot$ & - & 2 & 2 & & \\
\hline
\end{tabular}

$\begin{array}{lllllll}\text { Reg.-Bez. Orebro } & 22 & 38 & 60 & 22,32 & 37,43 & 29,99\end{array}$

Reg.-Bez. Västmanland (Land) $15 \quad 20 \quad 35$

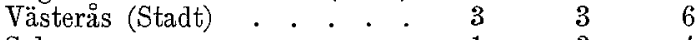

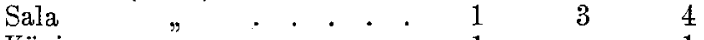

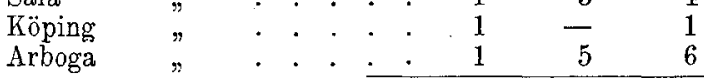

Reg.-Bez. Västmanland . $21 \quad 31 \quad 32 \quad 38,51 \quad 41,11 \quad 34,89$

Reg.-Bez. Kopparberg (Land) • $30 \quad 41 \quad 71$

Falun (Stadt) . . . . . . . $\quad 4 \quad 4 \quad 4 \quad 8$

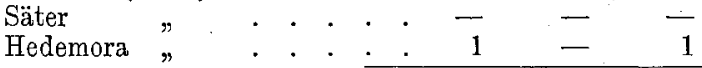

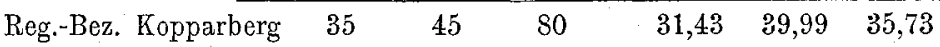

Reg.-Bez. Gäfleborg (Land) . . $\begin{array}{llll}17 & 29 & 46\end{array}$

Gäfle (Stadt). . . . . . . . $4 \begin{array}{llll}4 & 11 & 15\end{array}$

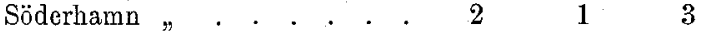

Hudiksvall $"$. . . . .

$\begin{array}{lllllll}\text { Reg.-Bez. Gäfleborg } & 24 & 42 & 66 & 19,68 & 33,81 & 26,81\end{array}$ 


\section{Zahl der Krebskranken}

Männer Frauen cul-
Zahl der Krebskranken auf 100000 Einwohner

Männer Frauen $\mathrm{zu}^{-}$

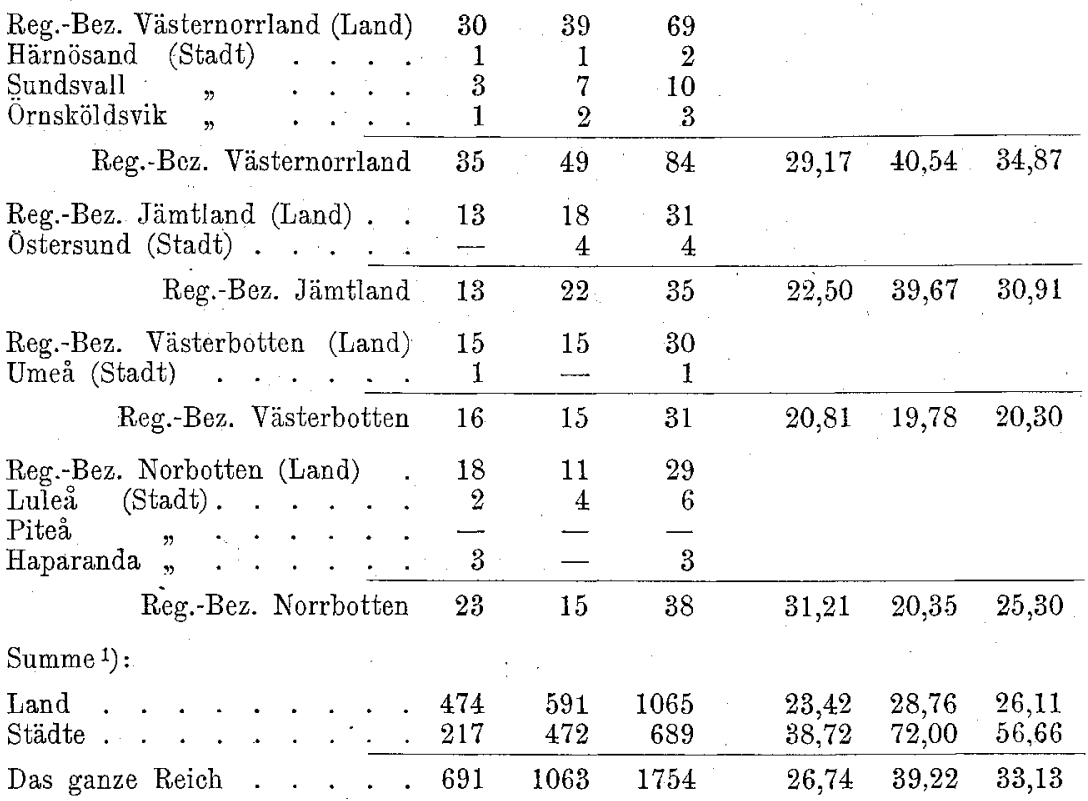

Wie aus der Tabelle hervorgeht, ist die Frequenz ${ }^{2}$ ) nicht für kleinere Gebiete als die Regierungsbezirke angegeben; in betreff der meisten Städte sind die Zahlen viel zu klein, um für eine zuverlässige Berechnung der Frequenz verwendet werden zu können.

Bei einem Vergleich zwischen der Frequenzziffer für sämtliche Städte $(56,66)$ und derjenigen für das Land $(26,11)$ erweist sich die Krebsfrequenz in den Städten mehr als doppelt so gross wie auf dem Lande. Hierans ist aber die Folgerung, dass der Krebs doppelt so häufig in den Städten sei als auf dem Lande, keineswegs gestattet. Es dürfte nämlich keinem $Z$ weifel unterliegen, dass die auf dem Lande vielerorts grossen Entfernungen von dem Arzte bewirken, dass man entweder ganz unterlässt oder länger als in den Städten zögert, ärztliche Hilfe zu suchen; während

1) Bei einem Vergleich zwischen den Zahlen für Land und Städte ist zu bemerken, dass zur Zeit der Sammelforschung das Land 76,8 pCt., die Städte 23,2 pCt. der Bevölkerung Schwedens umfassten.

2) Der Berechnung pro 100000 Einwohner ist die Einwohnerzahl am Ende des Jahres 1905 zugrunde gelegt worden. 
eines bestimmten Zeitraumes geben sich deshalb in den Städten eine relatir grössere Zahl von Fällen zu erkennen als auf dem Lande. Auch bei einem Vergleich zwischen den verschiedenen Regierungsbezirken in bezug auf die Krebsfrequenz ist aus ähnlichen Gründen eine gewisse Vorsicht angezeigt. So ist es z. B. nicht so ganz sichergestellt, dass die Krebsfrequenz der beiden nördlichsten Regierungsbezirke wirklich eine so niedrige ist, wie die angeführten Ziffern zu ergeben scheinen, und zwar aus dem Grunde, weil gerade in diesen Bezirken die grossen Entfernungen die Zurateziehung des Arztes öfters verhindern oder verzögern.

Im ganzen scheint die Krebsfrequenz verhältnismässig niedrig zu sein im südlichen Schweden, mit Ausnahme von Gotland und Blekinge, sowie in Norrland ${ }^{1}$ ) mit Ausnahme von Wester-Norrland, hoch dagegen in Svea Land. Die hohen Werte für den Regierungsbezirk Göteborg und Bohus erklären sich dadurch, dass der Bezirk eine verhältnismässig grosse Stadtbevölkerung hat. Lediglich auf das Land des Bezirkes berechnet, beträgt die Frequenz pro 100000 Einwohner 32,16, ein Wert, der.etwas niedriger ist, als der mittlere Wert für das ganze Reich $(33,13)$, und nicht viel höher als der mittlere Wert für das ganze Land.

Aus 20 Städten sind keine Krebsfälle gemeldet worden; die meisten dieser Städte sind ganz klein, unter ihnen finden sich doch solche mit 5000-10000 Finwohnern (Nyköping, Lidköping und Eksjö).

Bie Krebsfrequenz der Weiber ist erheblich höher als die der Männer; für das ganze Reich verhält sich der Frequenzwert der Weiber zu demjenigen der Männer wie $147: 100^{2}$ ). In den Städten ist die Differenz zwischen der Frequenz der beiden Geschlechter viel stärker ausgesprochen als auf dem Lande. Auf 100000 Einwohner kommen - wie aus Tabelle A ersichtlich - in den Städten 38,72 Krebsfälle männlichen, 72,00 weiblichen Geschlechts; für das Land sind die entsprechenden Zablen 23,42 männlichèn, 28,76 weiblichen Geschlechts. In der Stadt Stockholm ist die Frequenz mehr als doppelt so hoch bei den Weibern wie bei den Mänmern, und zwar 96,54 bei den Weibern, 46,15 bei den Männern. In 4 Regierungsbezirken: Kronoberg, Skaraborg; Västerbotten und Norrbotten ist die Frequenz höher bei den Männern als bei den Fraueu. Diese sämtlichen Bezirke

1) Seit Alters her besteht eine Einteilung des Reiches in Svea Land, Göta Land und Norrland. Svea Land umfasst die Regierungsbezirke Stockholm, Uppsala, Södermanland, Värmland, Örebro, Västmanland, Kopparberg. Norrland umfasst die nördlich von Svea Land gelegenen Regierungsbezirke, Göta Land die übrigen, südlichen.

2) Wenn der Vergleich sich auf das Alter über 20 Jahre beschränkt, ergibt sich das Verhältnis zwischen dem Frequenzwert des weiblichen und des männlichen Geschlechts wie $138: 100$ (vergl. T'abelle C.). 
zeichnen sich durch ihren geringen Prozentsatz städtischer Bevölkerung aus. Im übrigen ist zu bemerken, dass die absolute AnzahI der Krebsfälle in Regierungsbezirk Kronoberg sich genau gleich auf die beiden Geschlechter verteilt und yon so geringem Betrag ist, dass die Frequenzziffer in bedeutendem Masse vom Zufall abhängig sein muss; ferner sind, wie bereits angedeutet, die Zahlen für die beiden nördlichsten Regierungsbezirke wahrscheinlich zu niedrig.

Um eine bessere Uebersicht über die Krebsfrequenz in den verschiedenen Regierungsbezirken zu gestatten, ist die Frequenz für die Regierungsbezirke kartographisch wiedergegeben worden, wobei die Frequenzskala durch Berechnung der Krebsfälle auf 100000 Einwohner ausgedrückt wird und die Fälle in Gruppen von Fünfern oder Zehnern geordnet șind, eine Berechnung, die sowohl für beide Geschlechter zusaminen, wie besonders für das männliche und das weibliche Geschlecht durchgeführt worden ist (siehe die Tafeln I, II, III).

\section{Alter und Zivilstand ${ }^{1}$ ).}

In Tabelle B finden sich die Krebskranken nach Geschlecht, Alter ${ }^{2}$. - in Gruppen von 5 Jahren - und Zivilstand, besonders für das Land und für die Städte verteilt. In Tabelle $\mathrm{C}$ sind die absoluten Zahlen der Tabelle $\mathrm{B}$ in relative, d. h. in Frequenzzahlen umgerechnet worden ${ }^{3}$ ); ein Unterschied zwischen Land und Städten ist auf Grond der kleinen absoluten Zahlen nicht gemacht worden.

Unter den ermittelten Fällen findet sich keiner im Alter unter 20 Jahren.

Ganz niedrig im Alter von 20-25 Jahren, steigt die Frequenz schnell und gleichmässig bis zum Alter von 60-65 Jahren; dann erfolgt für die Gruppe von 65-70 Jahren ein auffallendes Sinken, das bei beiden Geschlechtern zu finden ist. Dann erhebt sich die Frequenzziffer wieder für das 70.-75. Jahr, wo sie bei beiden Geschlechtern ibr Maximum erreicht, um nachher wieder zu sinken. Das letzterwähnte Maximum ist fast dasselbe

1) d. h. ob ledig, verheiratet, verwitwet oder geschieden.

2) Das Alter ist dasjenige zur Zeit der Sammelforschung, nicht das beim ersten Erscheinen der Krankheit.

3) Beim Ausrechnen derselben sind die Bevölkerungszahlen des Jahres 1903 zur Anwendung gelangt, und zwar aus dem Grunde, weil zur Zeit des Ausarbeitens des Berichts die Verteilung der Bevölkerung nach Alter und Zivilstand für kein späteres Jahr bekannt war. Die Verschiebung von Jahr zu Jahr zwischen den verschiedenen Gruppen ist indessen so gering, dass der letzterwäKnte Umstand keinen nennenswerten Einfluss auf die Gültigkeit der Frequenzzahlen ausüben kann. 
Tabelle B. Die Krebskranken nach Geschlecht, Alter und Zivilstand gruppiert.

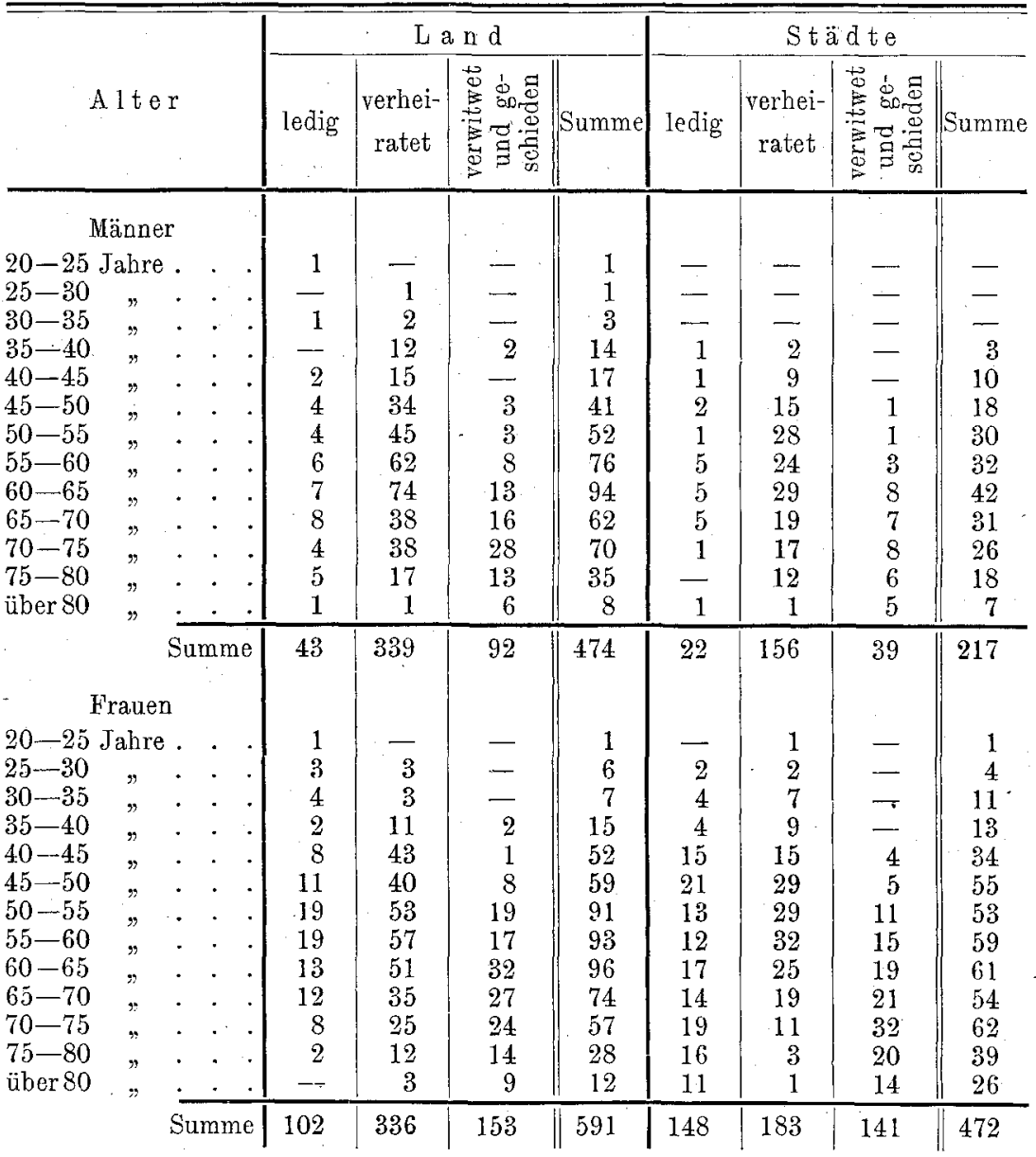

für Männer wie für Frauen (bei den ersteren 168,16, bei den letzteren 170,05 auf 100000 Einwohner).

Wie aus Tabelle B zu ersehen ist, entfällt die höchste Anzahl der Krebskranken auf das Alter von 60-65 Jahren und zwar sowobl für das männliche, wie für das weibliche Geschlecht.

In den beiden Gruppen von 60-65 und 75-80 Jahren, wo die Zahl der krebskranken Weiber absolut grösser als die der krebskranken Männer ist, ist jedoch die Krebsfrequenz etwas höber bei den Männern als bei den Frauen, was davon abhängt, dass die Anzahl der Weiber in diesen Altersklassen eine viel grössere ist, als die der Männer, z. B. in der Klasse von 
Tabelle c. Zahl der Krebskranken auf 100000 Einwohner innerhalb der verschiedenen Alters: und Zivilstandsgruppen.

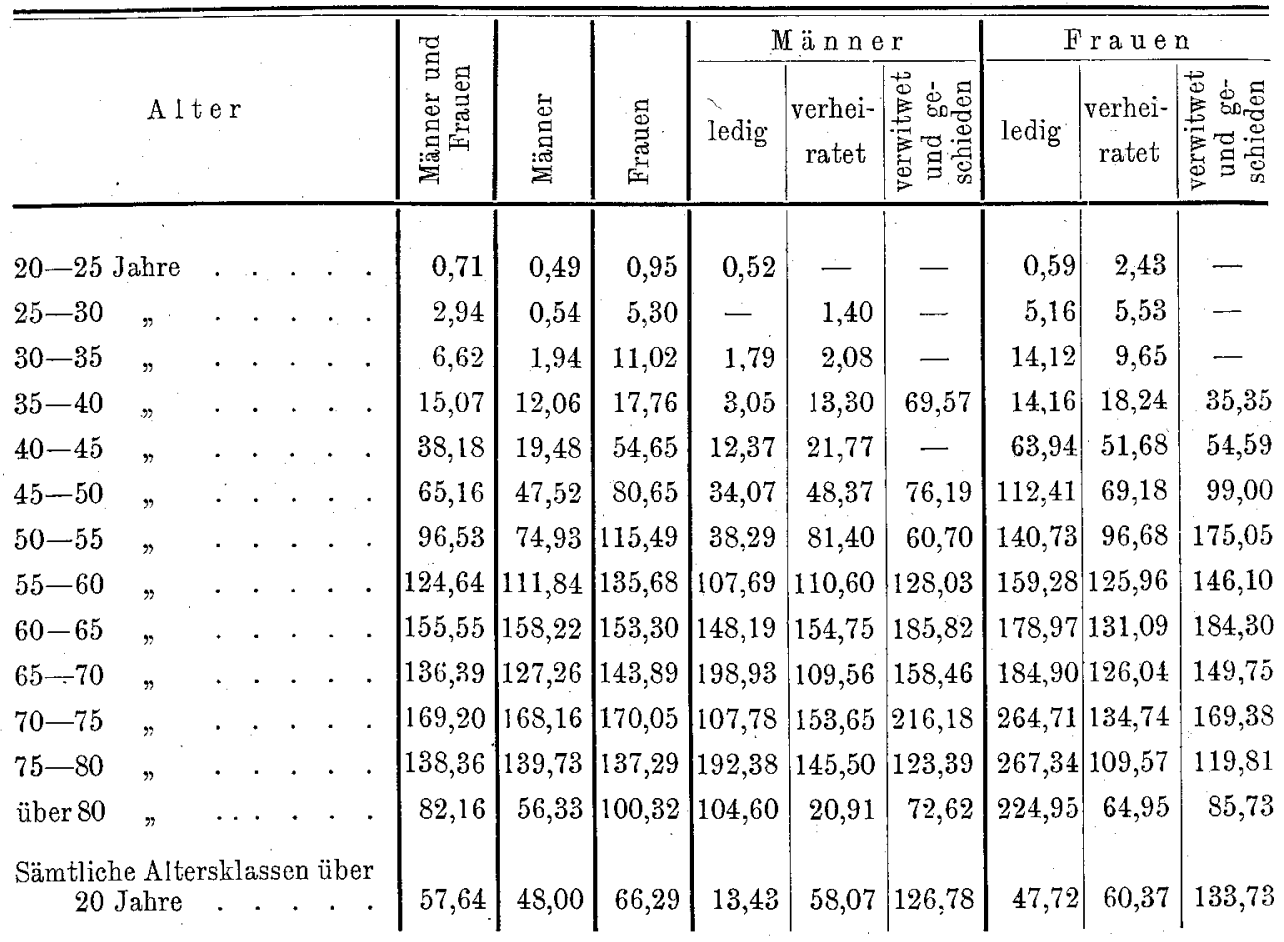

75-80 Jahren 1000 Männer auf 1287 Frauen. Das wechselnde Steigen und Sinken der Krebsfrequenz in den verschiedenen Altersklassen veranschaulicht die nebenstehende Kurve, welche die Anzahl der Krebsfälle männlichen und weiblichen Geschlechts auf 100000 Einwohner darstellt.

Vergleicht man die Frequenz in den verschiedenen Zivilstandsgruppen, so stellt es sich heraus, dass -- in sämtlichen Altern über 20 Jahre zusammengenommen - die Verheirateten öfter ergriffen sind, als die Ledigen, am allermeisten aber die Verwitweten. Die in höchstem Masse unregelmässigen Ziffern der verschiedenen Zivilstandskategorien innerhalb der männlichen Altersgruppe scheinen jedoch darauf hinzudeuten, dass auf Grund der Kleinheit der Ziffern der Zufall hier das Massgebende gewesen ist. Im übrigen ist zu betonen, dass das zusammengebrachte Material überhaupt so klein ist, dass bei einem statistischen Vergleich zwischen verschiedenen Teilen desselben Schlüsse nur mit grösster Vorsicht zu ziehen sind. 


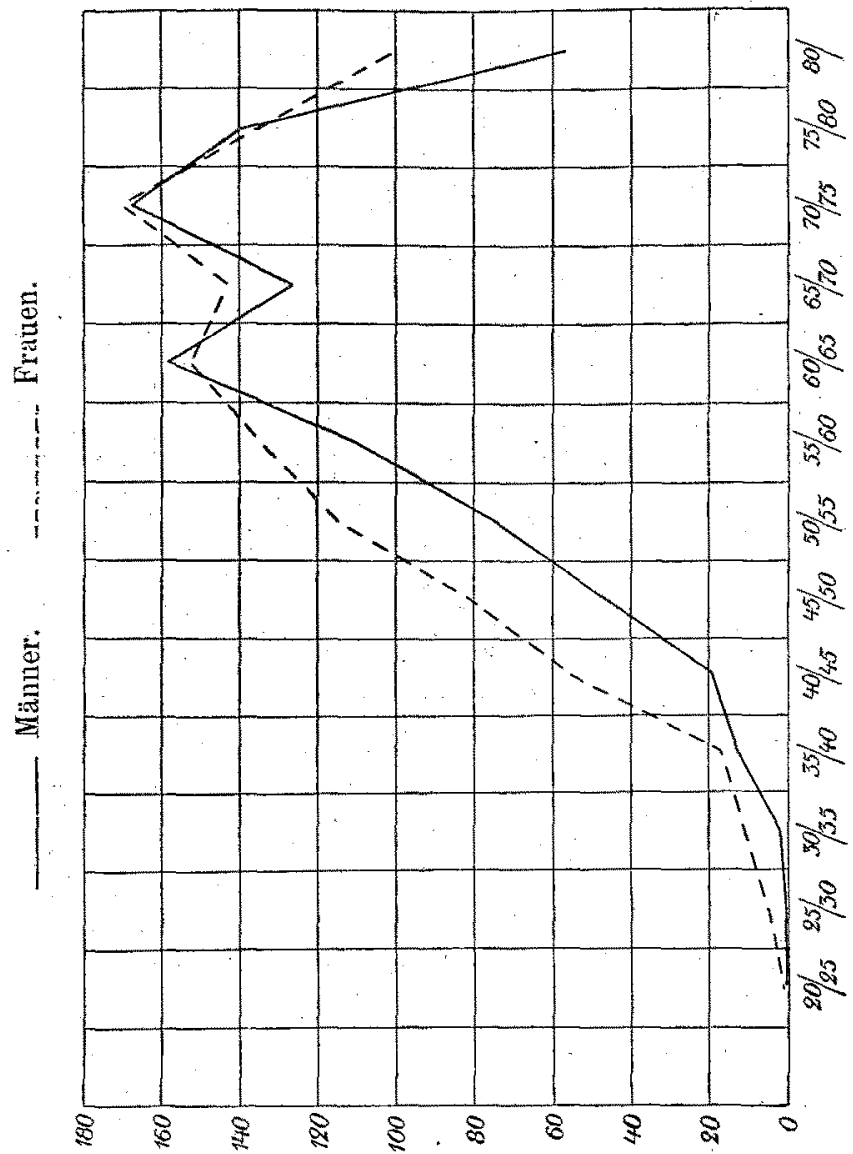

Die Frequenz ist beinahe ebenso gross bei verheirateten Männern wie bei verheirateten Frauen und desgleichen fast ebenso gross bei den Witwern wie bei den Witwen, viel grösser aber bei ledigen Franen als bei ledigen Männern.

\section{Zuerst befallenes 0rgan.}

In nachstehender Tabelle D finden sich die Krebskranken der verschiedenen Geschlechter und Altersklassen - gesondert für das Land und für: die Städte - nach demjenigen Organ gruppiert, wo der Krebs zuerst aufgetreten ist. 
Sammelforschung über die Krebskrankheit in Schweden.

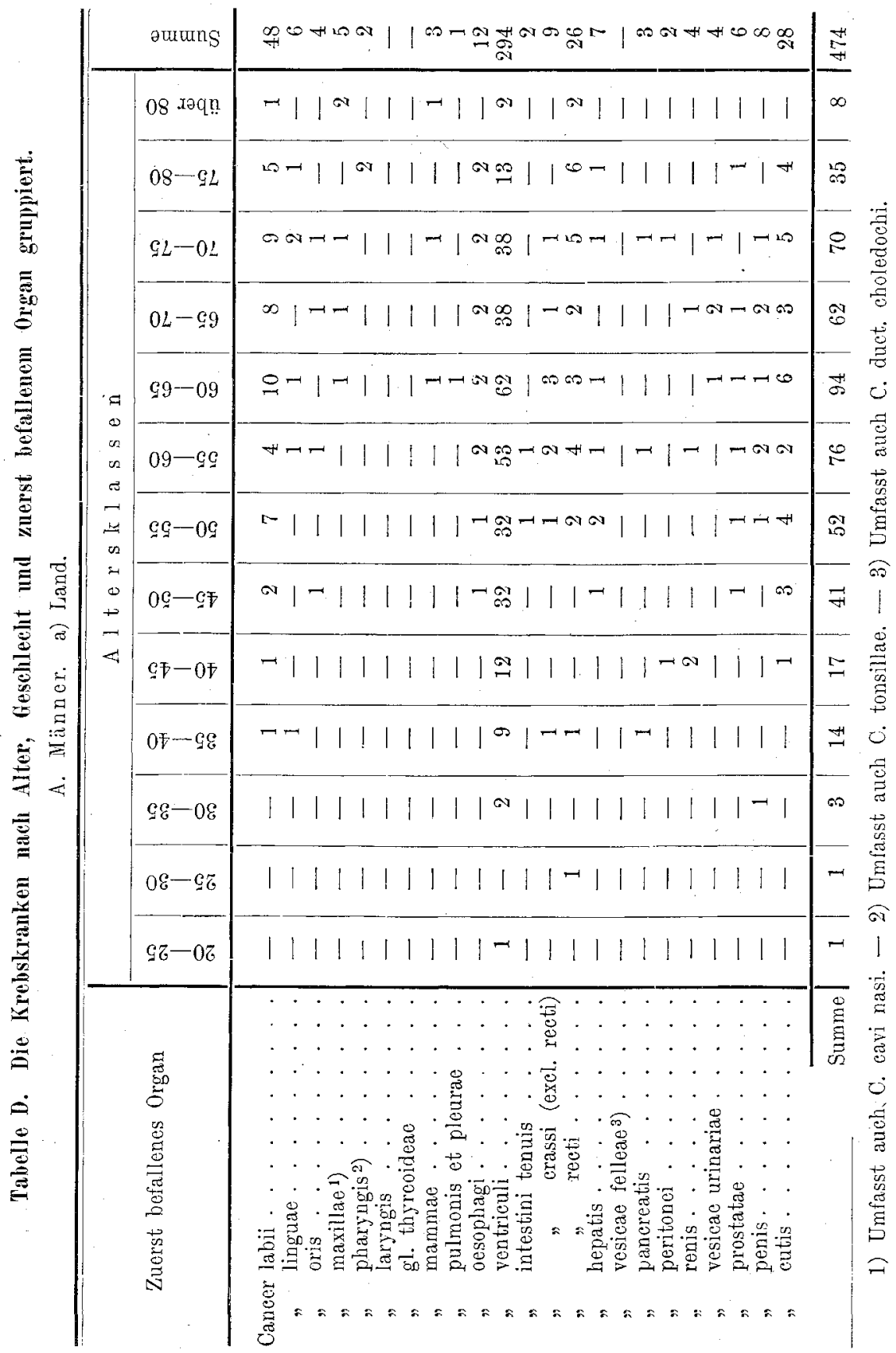




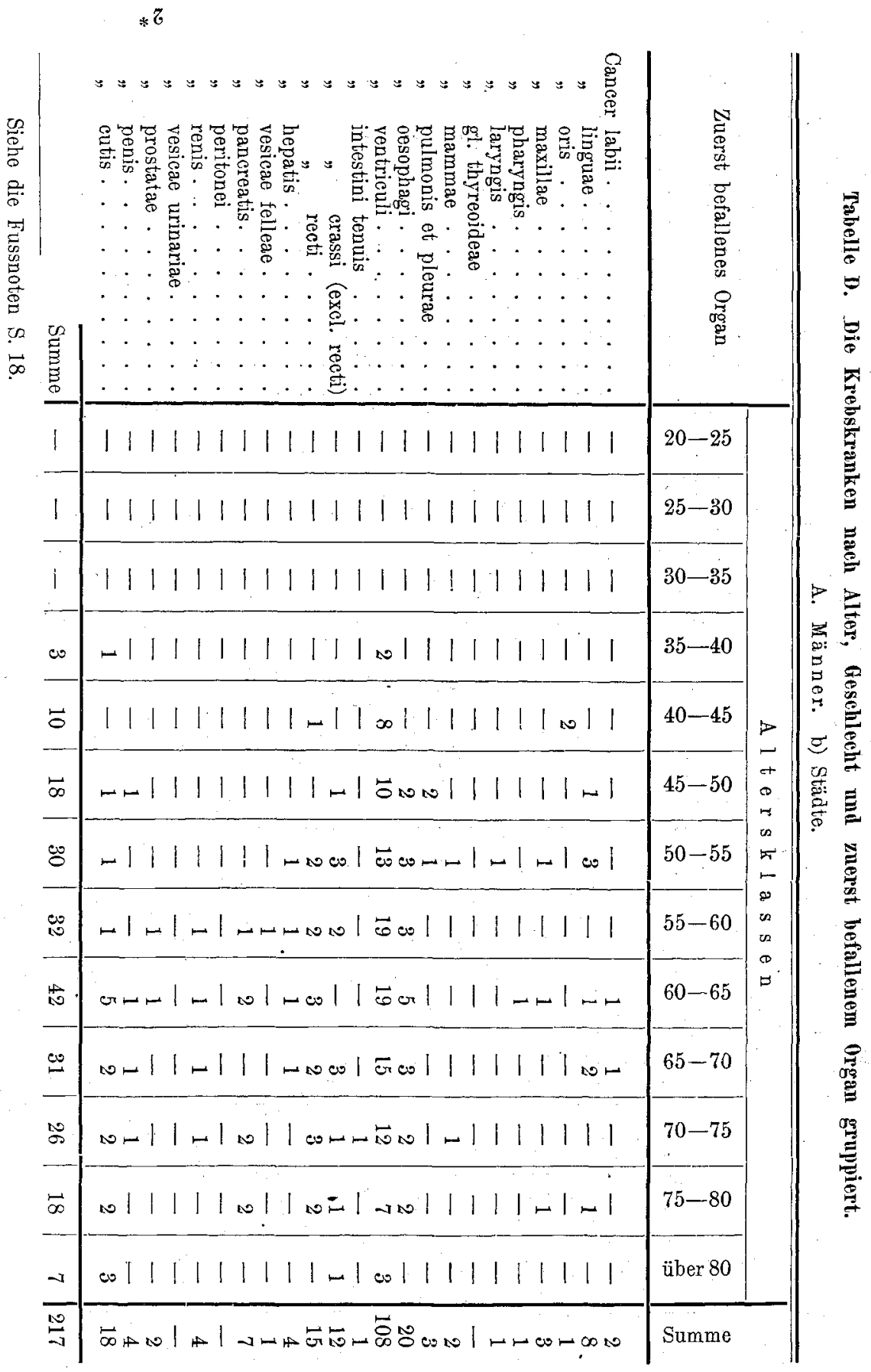


Sammelforschung über die Krebslmankheit in Schweden.

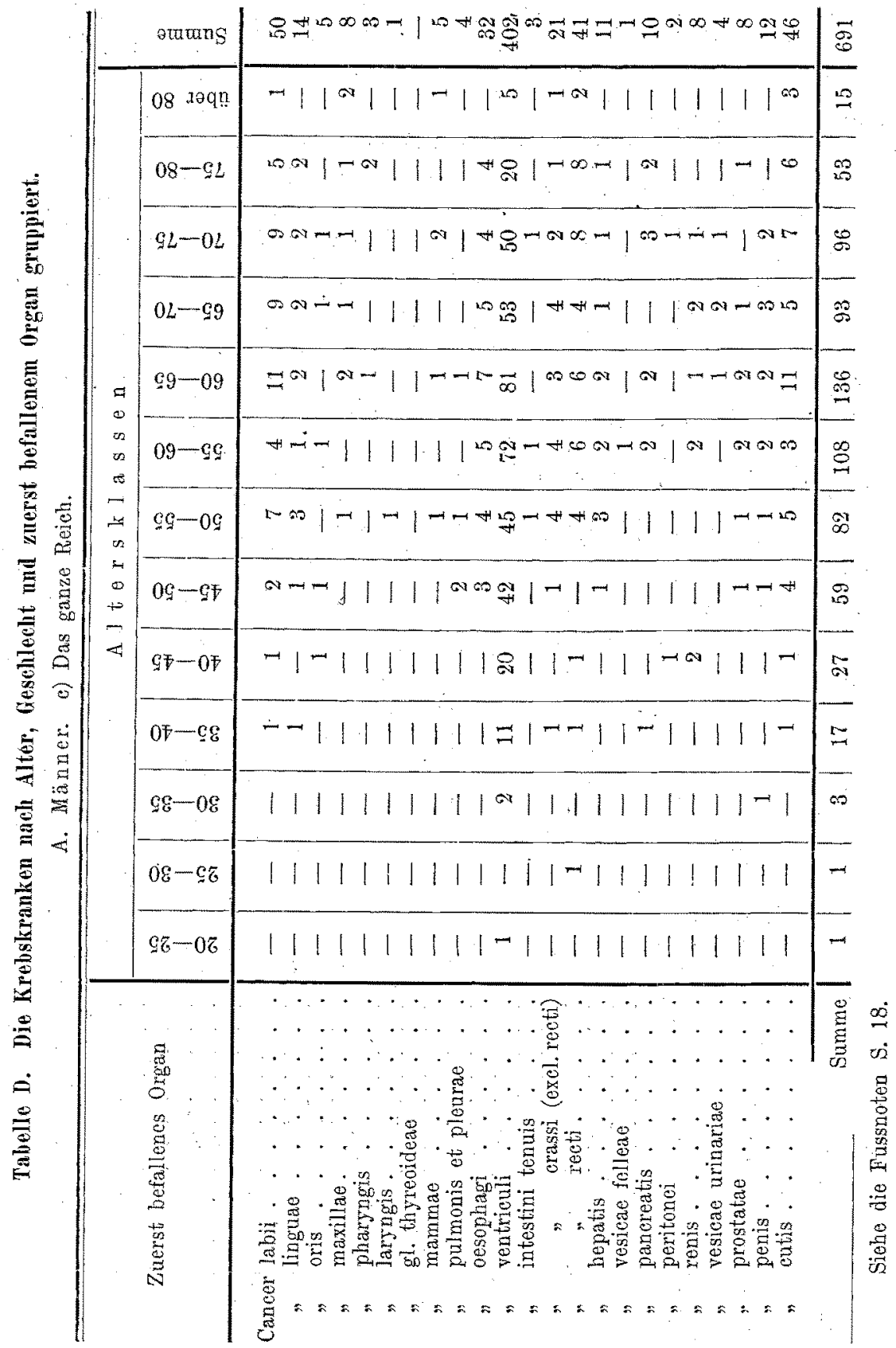




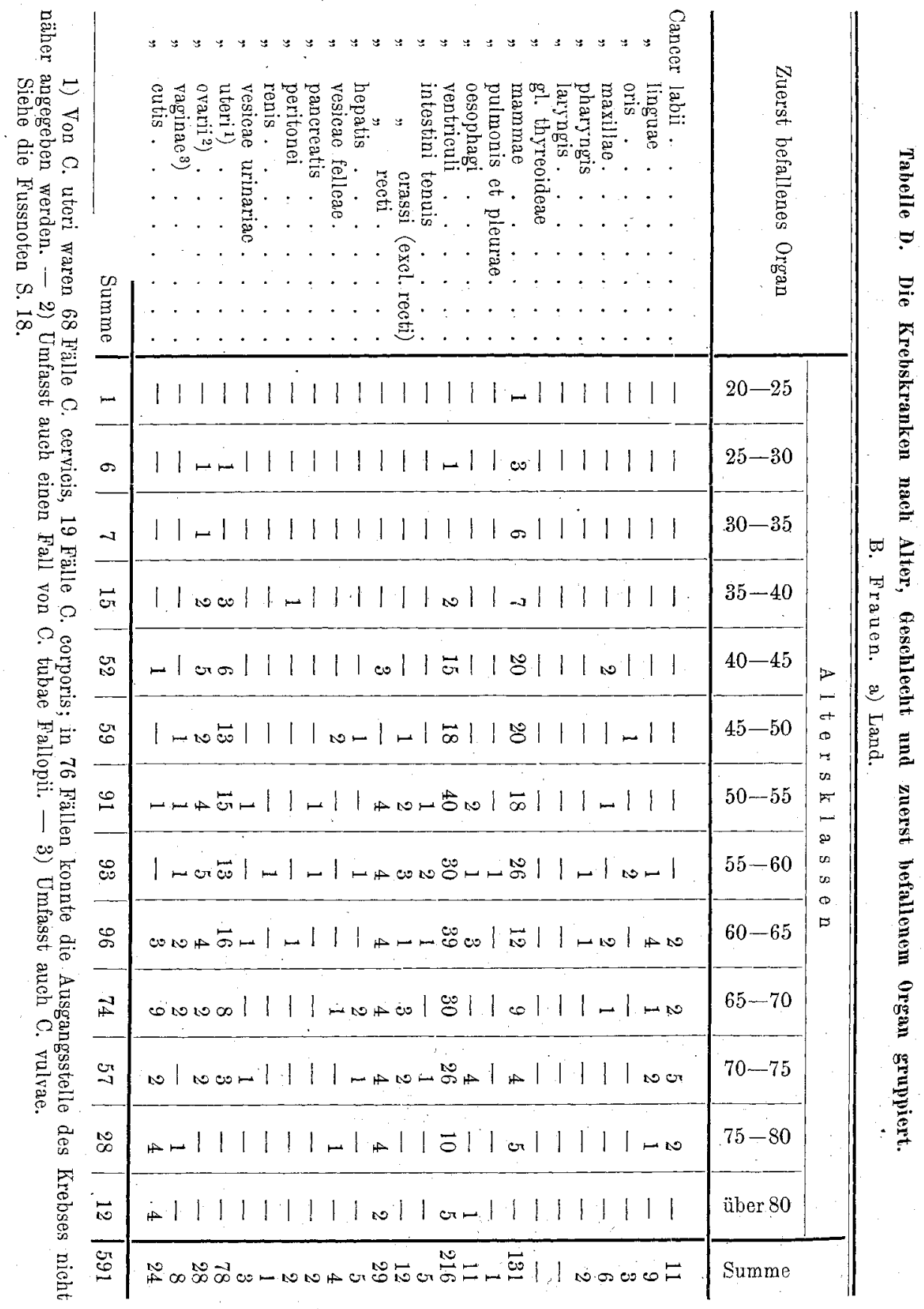


Sammelforschung über die Krebskrankheit in Schweden:

\begin{tabular}{|c|c|c|c|c|}
\hline & & әurung & 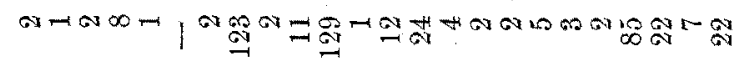 & $\stackrel{8}{5}$ \\
\hline & & 08 roqn & $\left.|1| 1||\right|^{n}|1=1-\infty| 1|-1|+-1 \infty$ & $\infty$ \\
\hline & & $08-92$ & 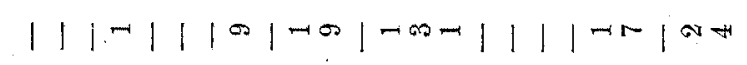 & की \\
\hline & & $9 L-0 L$ & $|1 \rightarrow \rightarrow| \rightarrow-\operatorname{ag} \rightarrow-\infty|1||||+| 10$ & 8 \\
\hline & & $02-69$ & ||||||$|\infty||0| \infty: \infty-1 \infty-100-\infty$ & 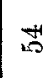 \\
\hline & $\begin{array}{l}a \\
0\end{array}$ & $99-09$ & 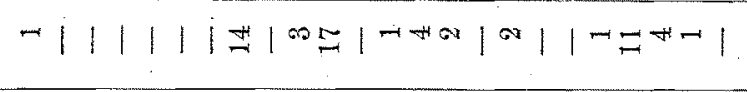 & 6 \\
\hline & $i^{\infty}$ & $09-\mathrm{eg}$ & 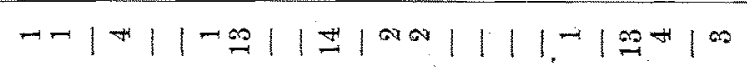 & 8 \\
\hline & $\vec{m}$ & $9 g-09$ & 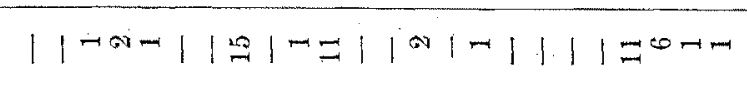 & 28 \\
\hline : & $\stackrel{+}{+\infty}$ & $09-q$ & 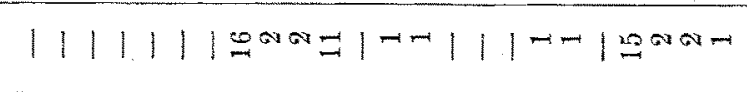 & 28 \\
\hline$\therefore$ & $\longleftrightarrow$ & $\subseteq \mp-0 \mp$ & 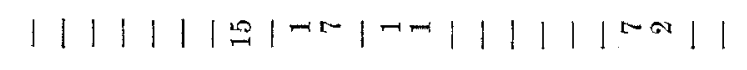 & की \\
\hline$\underset{m}{E}$ & & $0 \bar{T}-9 g$ & $1111111011011-1111110011^{-1}$ & $\stackrel{\oplus}{\oplus}$ \\
\hline "صر & & $9 \notin-0 \AA$ & 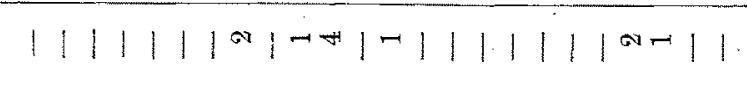 & $=$ \\
\hline & & $08-g z$ & $1|1| 1|1-1|-1|-1| 1|1|-111$ & 4 \\
\hline & & $9 z-0 z$ & $1111111111-1111111111111$ & - \\
\hline & & 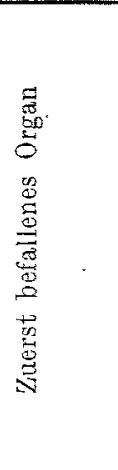 & 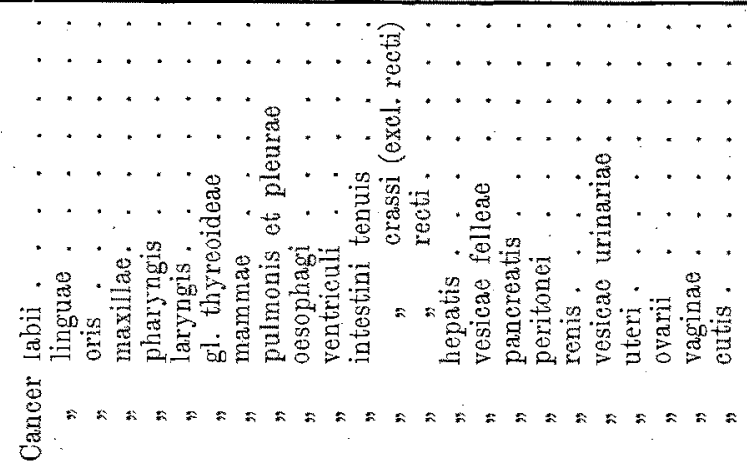 & 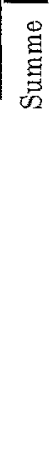 \\
\hline
\end{tabular}


Sammelforschung über die Krebskrankheit in Schweden.

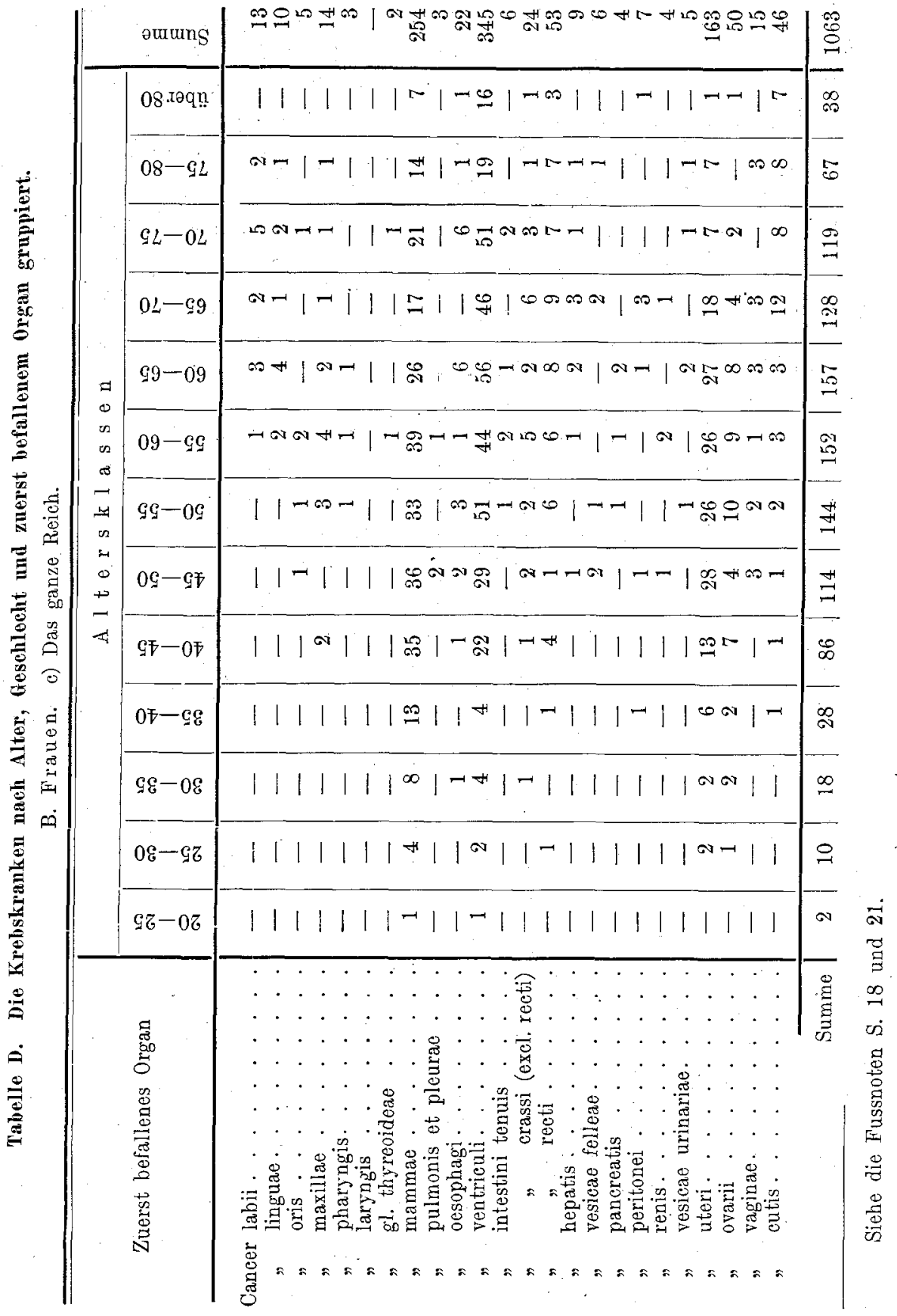


Bereits aus den in Tabelle D mitgeteilten absoluten Zahlen ergibt sich, in welchen Organen der Krebs am häufigsten vorkommt. Noch deutlicher erhellt dies aus nachfolgender Tabelle, welche die prozentische Verteilung des Krebses auf die verschiedenen Organe angibt.

Tabelle E. Die prozentische Verteilung des Krebses auf die verschiedenen Organe.

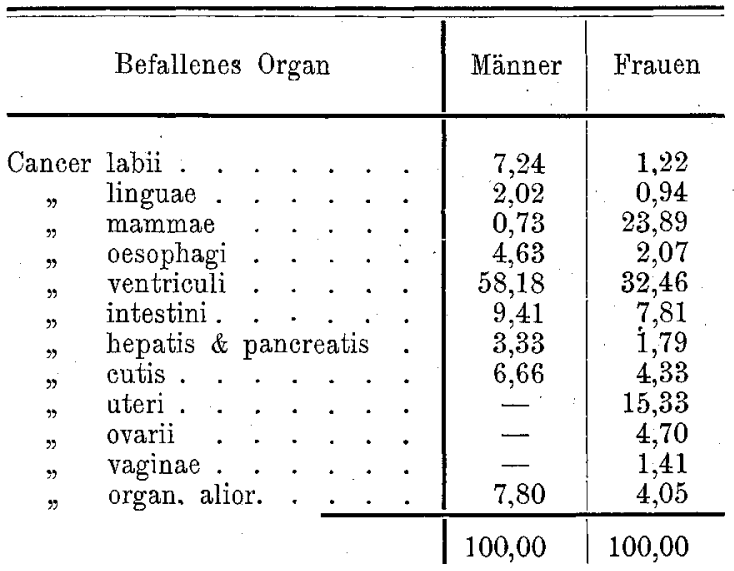

Aus den obenstehenden Tabellen $\mathrm{D}$ und $\mathrm{E}$ ergibt sich, dass die häufigste Lokalisation des Krebses sowohl bei dem männlichen wie bei dem weiblichen Geschlecht im Ventrikel ist. Doch besteht ein bedeutender Unterschied zwischen den prozentischen Zahlen der Männer und denjenigen der Frauen, indem der Magenkrebs bei den ersteren 58,18 pCt. von sämtlichen Fällen ausmacht, bei den letzteren 32,46 pCt., eine Differenz, die durch die hohen Ziffern für den Krebs der weiblichen Geschlechtsorgane erklärt wird.

Das nachfolgende Diagramm zeigt in einer noch anschaulicheren Weise die Verteilung des Krebses auf die verschiedenen Organe.

Früher ist, sowobl tabellarisch wie kartographisch, eine Gruppierung der Krebskranken nach Regierungsbezirken mitgeteilt worden; es dürfte von Interesse sein, für jeden Regierungsbezirk auch eine Gruppierung nach dem zuerst befallenen Organ durchzufübren. (Siehe Tabelle F.)

In betreff der grössten Gruppe, nämlich derjenigen des Magenkrebses, ist es von Interesse, die Zahl der Fälle auf 100000 Einwohner für die verschiedenen Regierungsbezirke und die 3 grössten Städte zu berechnen. Aus einer derartigen Berechnung ergeben sich die Ziffern der Tabelle auf Seite 28. 
Sammelforschung über die Krebskrankheit in Schweden.

Männer

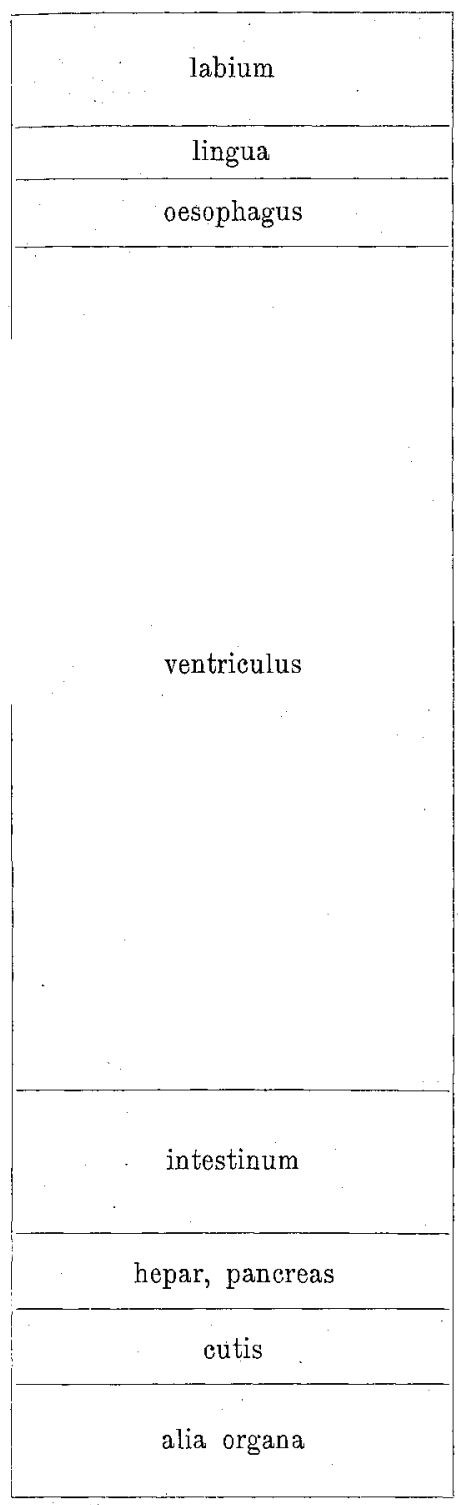

Frauen

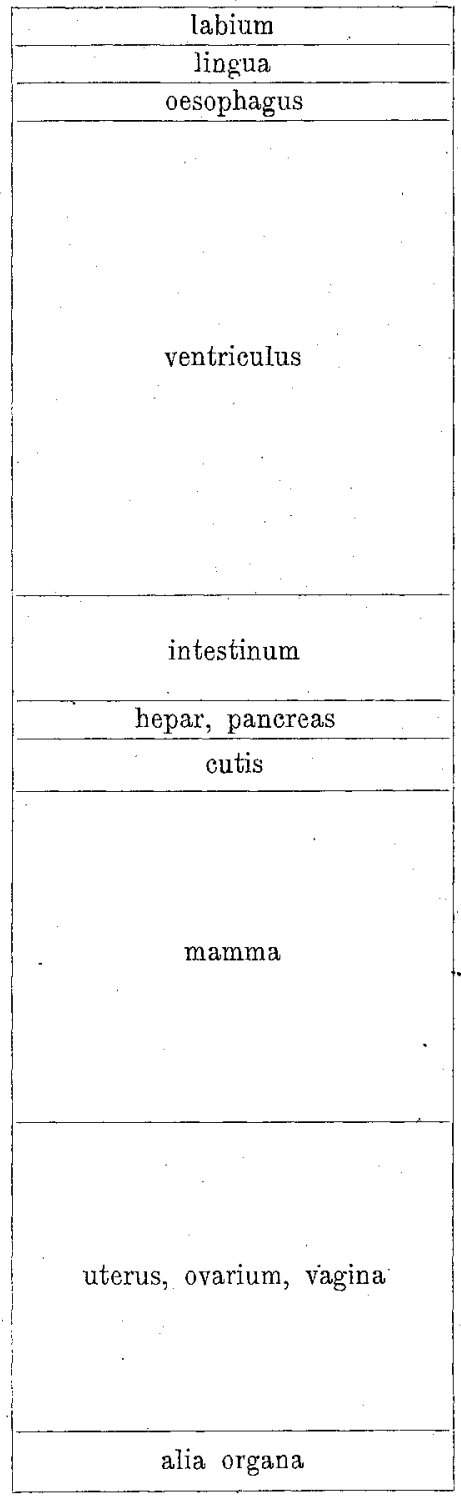

Hieraus erhellt, dass für die Männer die Frequenz des Magenkrebses in 10 Regierungsbezirken grösșer und in 14 Regierungsbezirken kleiner ist als der mittlere Wert für das ganze Reich. Die grösste Frequenz findet 
Sammelforschung über die Krebskrankheit in Schweden.

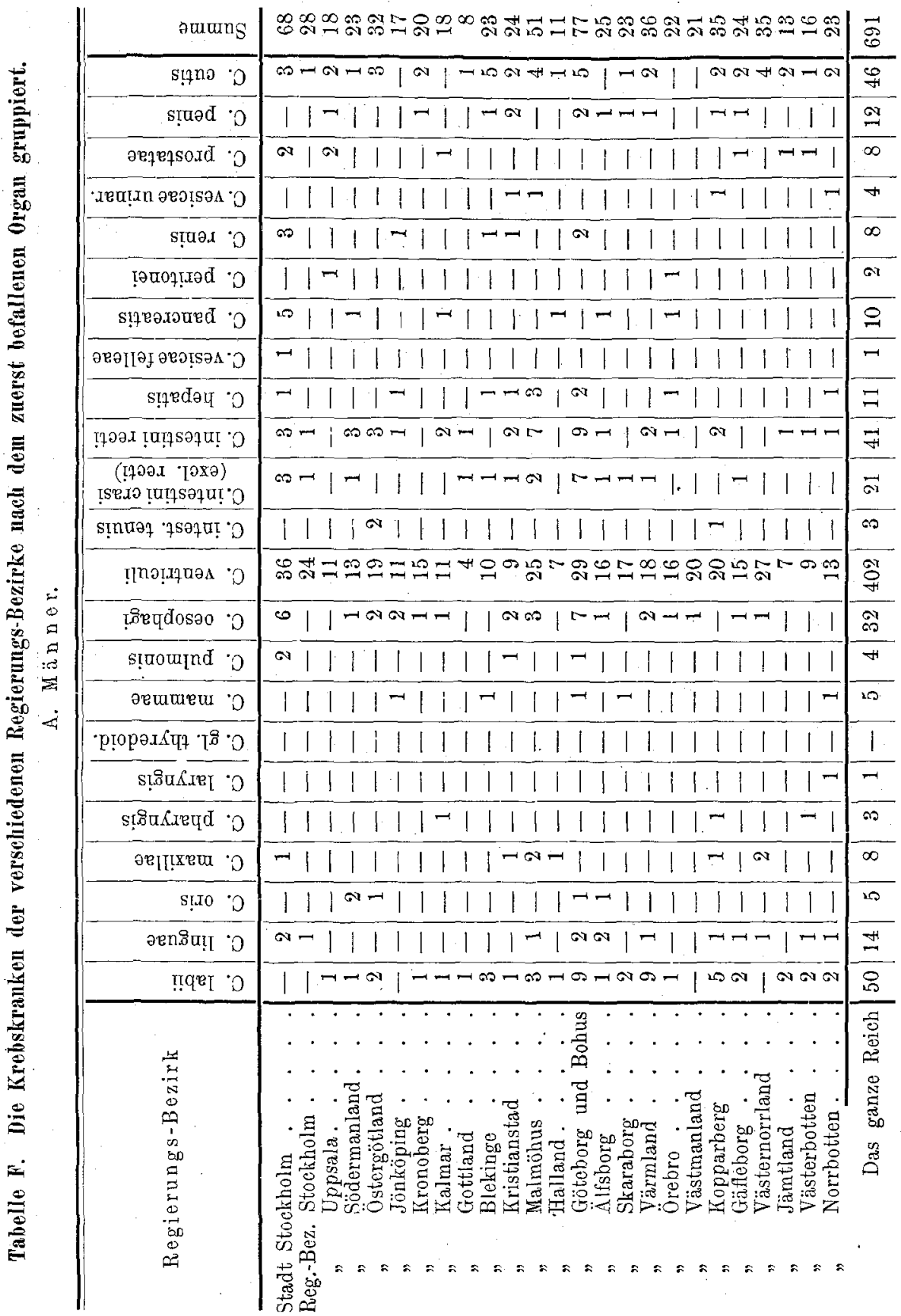


Sammelforschung über die Krebskrankheit in Schweden.

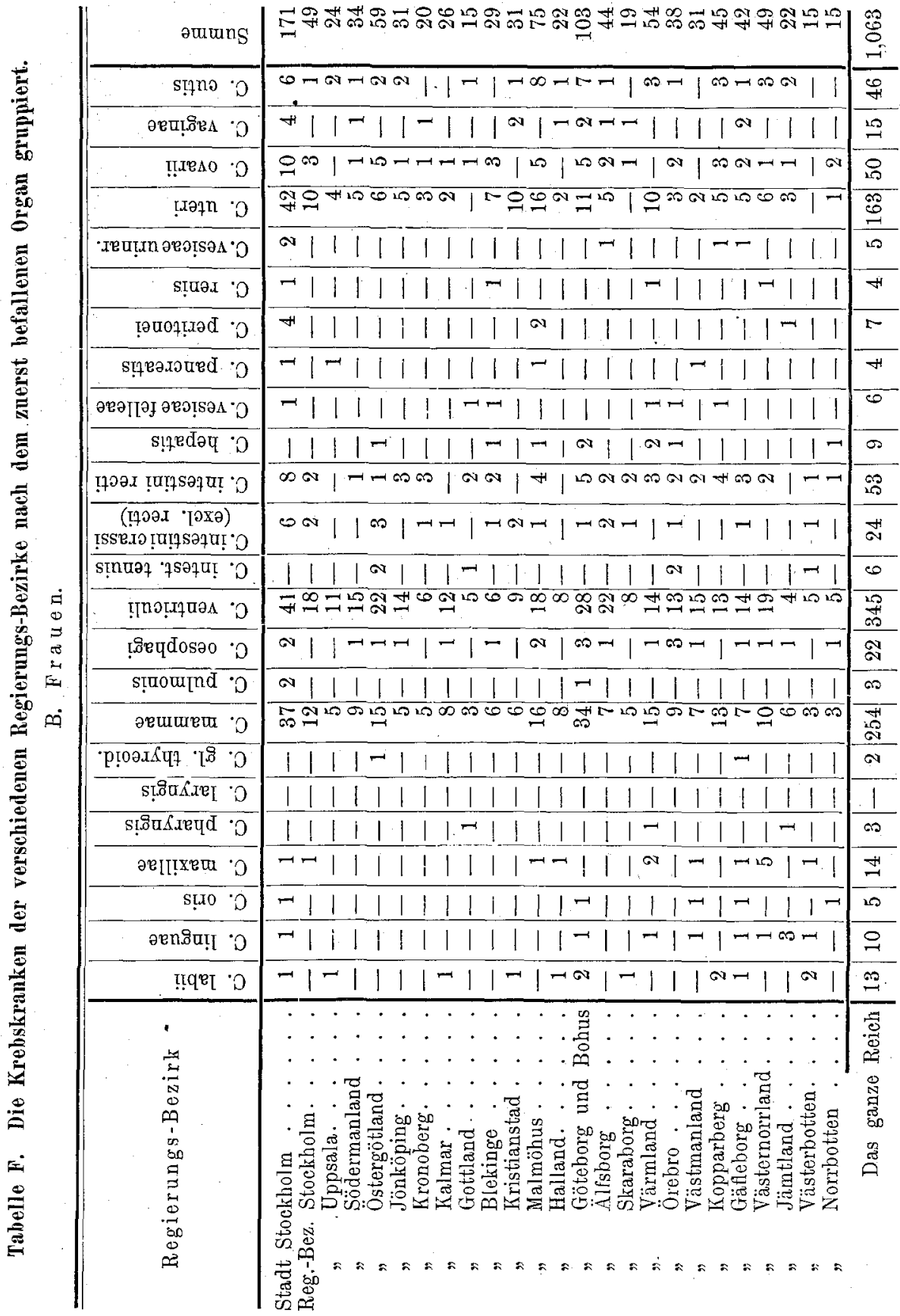




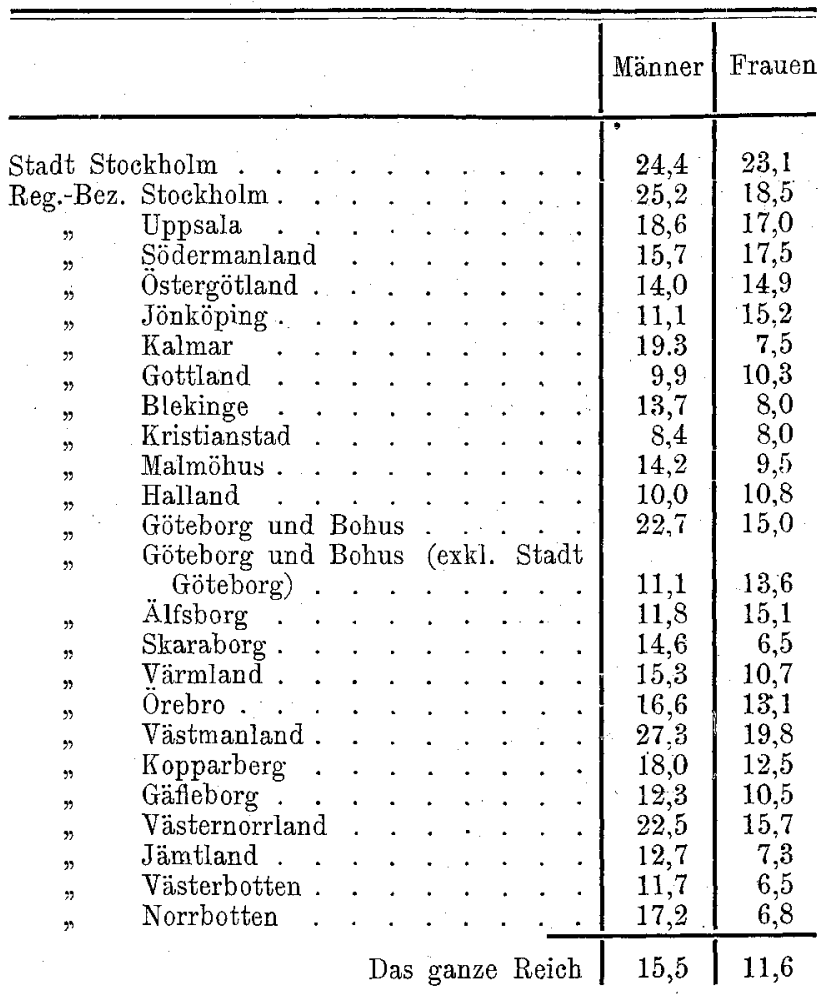

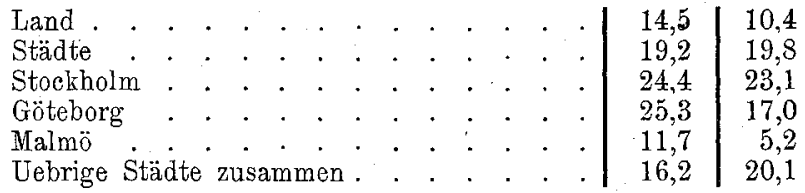

sich im Regierungsbezirk Västmanland $(27,3),{ }^{1}$ ) die kleinste Frequenz im Regierungsbezirk Kristianstad (8,4). Für die Stadt Stockholm ist die Frequenzziffer bedeutend höher als der mittlere Wert für das ganze Reich und ebenfalls beträchtlich höher als der mittlere Wert für die Städte.

Für das weibliche Geschlecht ist die Frequenz des Magenkrebses in 12 Regierungsbezirken grösser und in 12 Regierungsbezirken kleiner als der mittlere Wert für das Reich; die grösste Frequenz findet sich im Regierungsbezirk Västmanland $(19,8)$, die kleinste $(6,5)$ in den Regierungs-

1) Als eigentümlich verdient bemerkt zu werden, dass im Regierungsbezirk Västmanland von sämtlichen 21 Krebsfällen männlichen Geschlechts 20 Fälle Magenkrebs waren. 
bezirken Skaraborg und Västerbotten. Die grösste Frequenz (23,1) bat jedoch die Stadt Stockholm aufzuweisen.

Es bestehel demnach grosse Differenzen in bezug auf die Verbreitung des Magenkrebses in den verschiedenen Teilen des Reiches, sowohl für die Männer wie für die Frauen. Weil die Zahlen zu klein sind, dürfte indessen diesen Verhältnissen keine grössere Bedeutung zugeschrieben werden können.

In betreff des Vorkommens des Magenkrebses in verschiedenen Altern zeigt Tabelle D, dass vor dem 20. Jahre kein Fall und in der Altersklasse 20-25 Jabre nur 2 Fälle beobachtet worden sind. Im übrigen geben die absoluten Zahlen weniger Aufklärung über die wirkliche Frequenz, weshalb in nachstehender Tabelle $G$ die Frequenzziffern auf 100000 Einwohner mitgeteilt sind.

Tabelle G. 'Die Frequenz des Magenkrebses in den verschiedenen Altersklassen mänmlichen und weiblichen Geschlechts, in den Stälten und anf dem Lande, anf 100000 Einwohner.

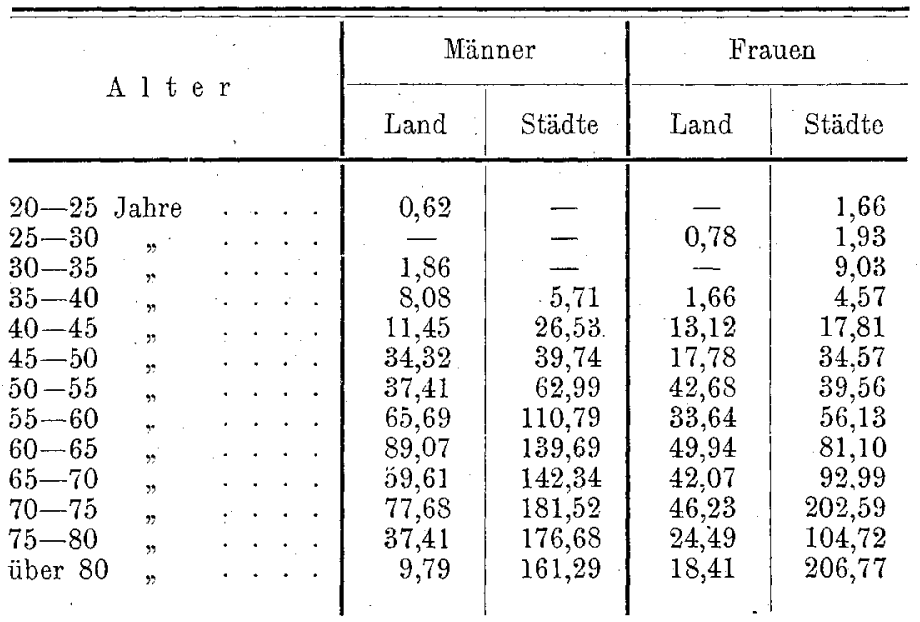

Aus der Tabelle ergibt sich, dass bei beiden Geschlechtern der Magenkrebs beinahe in sämtlichen Altersklassen beträchtlich häufiger ist in den Städten als auf dem Lande. In bezug auf die Frequenz der verschiedenen Altersklassen kann auf Grund des geringen Umfanges des Materials keine grössere Bedeutung den Ziffern beigemessen werden. Jedoch dürfte aus obenstehender Tabelle die Folgerung berechtigt sein, dass das Frequenzmaximum für das ganze Reicb, sowohl für die Männer wie für die Frauen, sich im Alter von $70-75$ Jahren findet.

Der Magenkrebs ist die einzige beiden Geschlechtern gemeinsame Krebsform, welche eine so grosse Auzahl von Fällen aufzuweisen hat, dass der Versuch einer eingebenderen Bearbeitung berechtigt erscheint. 
Betreffend die Grösse des Materials kommt der Krebs der weiblichen Geschlechtsorgane (Cancer mammae, uteri, ovarii, vaginae) dem Magenkrebs am nächsten. Laut Tabelle D beträgt die Anżahl der Falle von Krebs der Brustdrüse bei Franen 254, wovon 123 in den Städten, 131 auf dem Lande, die entsprechenden Ziffern für den Gebärmutterkrebs sind 163, 85 und 78. Die genannten Ziffern, mit der relativen Grösse der Städte- und Landbevölkerung verglichen, ergeben, dass sowohl der Brustdrüsen- wie der Gebärmutterkrebs bei weitem häufiger in den Städten als auf dem Lande ist. Berechnet man die Anzahl der Fälle auf 100000 Einwohner, so ergeben sich für den Brustdrüsenkrebs nachstehende Ziffern: 6,3 Falle auf dem Lande, 18,7 in den Stadten nnd 9,3 für das ganze Reich, für Stockholm, Göteborg und Malmö ergeben sich die Ziffern 24,5, 26,8 und 8,0 . Die entsprechende Berechnung für den Gebärmutterkrebs gibt folgende. Ziffern: 3,7 Fälle anf dem Lande, 11,8 in den Städten und 6,0 für das ganze Reich; für Stoekholm, Göteborg und Malmö sind die Ziffern; 23,7, 10,9 und 18,4 .

In betreff desjenigen Alters, bei welchem der Krebs der weiblichen Geschlechtsorgane in Erscheinung tritt, ist es der Beachtung wert, dass derselbe, mit dem Krebs anderer Organe verglichen, relativ häufiger ist in dem Alter unter 40 Jahre, und zwar:

für Cancer mammae in 10,2 pCt. sämtlicher Fälle von Cancer mammae

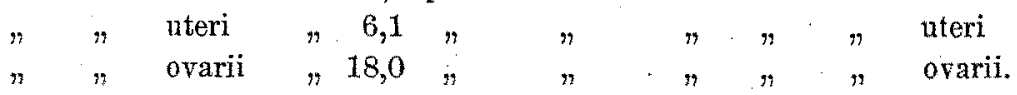

Was die primäre Lokalisation des Krebses in übrigen Organen betrifft, so sind die Ziffern des vorliegenden Materials zn klein, um eine eingehendere statistische Bearbeitung zu erlauben. Einige Verhaltnisse, die aus der im Vorigen mitgeteilten Tabelle $D$ hervorgehen, dürften jedoch einer Erwähnung wert sein.

Den Darmkrebs anlangend, ist der Rektumkrebs doppelt so hăufig wie der Krebs der übrigen Abschnitte des Darms. Ferner ist zu erwähnen, dass der Darmkrebs häufiger ist bei Frauen als bei Männern, ein Sachverbalt, der durch das bedeutende Ueberwiegen des Rektumkrebses bei den Frauen bedingt ist.

Auffallend ist auch die verschiedene Verteilung des Lippenkrebses auf das Land und die Städte: 59 Falle auf dem Lande und 4 in den Städten. Von sämtlichen diesen Fallen sind 50 männlichen, 13 weiblichen Geschlechts. Ferner ist aufmerksam $\mathrm{zu}$ machen auf die relativ hohen Zahlen des Lippenkrebses des wännlichen Geschlechts in den Regierungsbezirken Värmiand und Kopparberg, wie auch in den Regierungsbezirken Blekinge und Göteborg.Bohus. 
Wenn man sämtliche Fälle von Lippenkrebs männlichen Geschlechts in den "Regierungsbezirken Vämland, Kopparberg und Göteborg-Bohus zusnmmenrechnet, machen sie beinahe die Hälfte sämtlicher Fäle von Lippenkrebs beim männlichen. Geschlecht im ganzen Reich aus. Von den Fallen von Lippenkrebs sind beim männlichen Geschlecht nur 1 zur Oberlippe lokalisiert, von den 13 Fällen beim weiblichen Geschlecht 4.

Kon Hautkrebs kamen bei jedem Geschlecht 46 Fälle vor; von diesen sind 60 zur Gesichtshaut lokalisiert, 22 Fälle unter den Männern, 38 unter den Weibern. Auf 100.000 Einwohner berechnet kommen für das ganze Reich 1,7 auf die Männer, 1,6 auf die Weiber; für die Städte sind die entsprechenden Ziffern 3,2 und 3,3 ; für das Land 1,3 und 1,1 .

Der Speiseröhrenkrebs findet sich auf dem Lande in 23 Fällen; in den Städten in 31 Fallen, also im Verhälnis zur Einwohnerzahl bei weitem häufiger in den Städten als auf dem Lande. Besonders auffallend ist das grosse Ueberwiegen des männlichen Geschlechts in bezug auf die Frequenz in den Städten.

\section{Duration, Metastasen usw.}

Was diejenigen Krebskranken betrifft, die während der Sammelforschungszeit gestorben sind, so ist es möglich gewesen, mit Kenntnis von dem Zeitpunkte für das Erscheinen der ersten Krankheitssymptome die Dauer der Krankheit von diesem Zeitpunkt an bis zum Eintreffen des Todes zu berechnen. In bezug anf die zur Zeit der Beendigung der. Sammelforschnng noch Ueberlebenden ist es selbstverständlich nicht möglich gewesen, eine Berechnung über die Duration der Krankheit auszuführen. Fs dürfte jedoch von Interesse sein, die Zeit von dem Auftreten der ersten Krankheitserscheinungen an bis zum Ende der Observationszeit zu kennen. Die Ergebnisse der diesbezüglichen Berechnung finden sich in Tabelle $\mathrm{H}$.

Die meisten Todesfälle entfallen auf die Gruppe Magenkrebs. Von diesen Fallen hat sich die Krankheitsdaner in 60 pCt. auf 1 Jahr oder weniger belaufen. Dem Magenkrebs am nächsten in bezug auf die Zahl der Todesfälle kommt der Brustdrüsenkrebs, der in 40 pCt. der Fälle eine Duration von $11 / 2$ Jahr oder weniger, in 17 pCt. eine Duration von mehr als 9 Jahren aufweist.

Was die zur Zeit des Schlusses der Forschnngszeit taberlebenden Krebskranken betrifft, so ist hervorzuheben, dass die Duration in 8 Fällen von Hautkrebs mehr als 20 Jahre betragen hat; in 25 Fallen hat sich die Duration auf 10-20 Jahre belanfen, wovon 7 Falle auf Haut-, 6 auf Lippen-, 9 auf Brustdrüsen-, 2 auf Seheiden- und 1 anf Gebärmutterkrebs entfallen. 
Die Frage von der Metastasierung des Krebses hat sich durch das vorliegende Material in keiner Weise aufklären lassen.

Wie aus dem Frageblatt ersichtlich ist, waren Auskünfte auch über vorgenommene Operationen verlangt worden. Es hat sich aber herausgestellt, dass das hierüber vorliegende Material zu der für die Sammelforschung gestellten Aufgabe nicht hat: verwertet werden können.

\section{Beruf.}

Natürlich wäre es von grossem Interesse, nachzuweisen, inwiefern der Beruf für das Auftreten des Krebses in diesem oder jenem Organ von Bedeutung wäre. Eine derartige Untersuchung erheischt indessen in erster Linie genaue Kenntnis von der Verteilung der Bevölkerung auf die verschiedenen Berufe oder Erwerbstätigkeiten. Bekanntermassen gehören aber die Berufsangaben zu den grössten Schwächen der schwedischen Statistik, ganz abgesehen von dem Umstande, dass derartige Angaben nur bei den Volkszählungen jedes 10. Jahr eingesammelt werden. ${ }^{1}$ ) Es. kommt hinzu, dass in dem vorliegenden Material die Berufsangaben in den ausgefüllten Frageblättern nicht selten sebr schwebend sind. Eine Tabelle über die Krebsfrequenz in den verschiedenen Berufsarten würde deshalb, vorausgesetzt, dass es möglich wäre, eine solche Tabelle zu errichten, Zahlen aufweisen, die von sehr zweifelhaftem Werte oder vielleicht ganz irreleitend wären. Indessen hat das Komitee den Versuch nicht unterlassen wollen, eine Gruppierung nach angeblichem Beruf oder Erwerb durchzuführen. Von den Frauen hat jedoch mehr als die Hälfte unter einer der Gruppen „verheiratete ohne eigenen Beruf" oder „Witwen obne Angabe des Berufs" einbegriffen werden müssen (s. Tabelle I).

In nahem Zusammenhang mit der Frage von dem Einfluss des Berufs steht diejenige von dem Vorkommen des Krebses in den verschiedenen Gesellschaftsklassen. Hierüber kann das zusammengebrachte Material keine nähere Antwort geben. Wenn man indessen, zwecks einer ungefähren Trennung der besser situierten oder gebildeten Klassen von den übrigen, diejenigen männlichen Krebskranken in eine Gruppe unterbringt, die entweder Gutsbesitzer sind oder irgendeinen Beruf treiben, der böhere Studien oder Kapital voraussetzt, und in eine zweite Gruppe alle übrigen (auch Handwerker, wegen der Unmöglichkeit, sie von den Arbeitern der handwerklichen Erwerbe zu trennen), würde sich eine Gruppe von 273 Krebskranken, den besser situierten Klassen angehörend; und eine von 418, den schlechter situierten Klassén angehörend, ergeben. Ein Vergleich zwischen

1) Die jährlichen Berufsangaben, die sich in den Berichten des Kommerzkollegiums finden, beziehen sich nur auf die Arbeiter gewisser industrieller Berufe. 
Sammelforschung über die Krebskrankheit in Schweden.

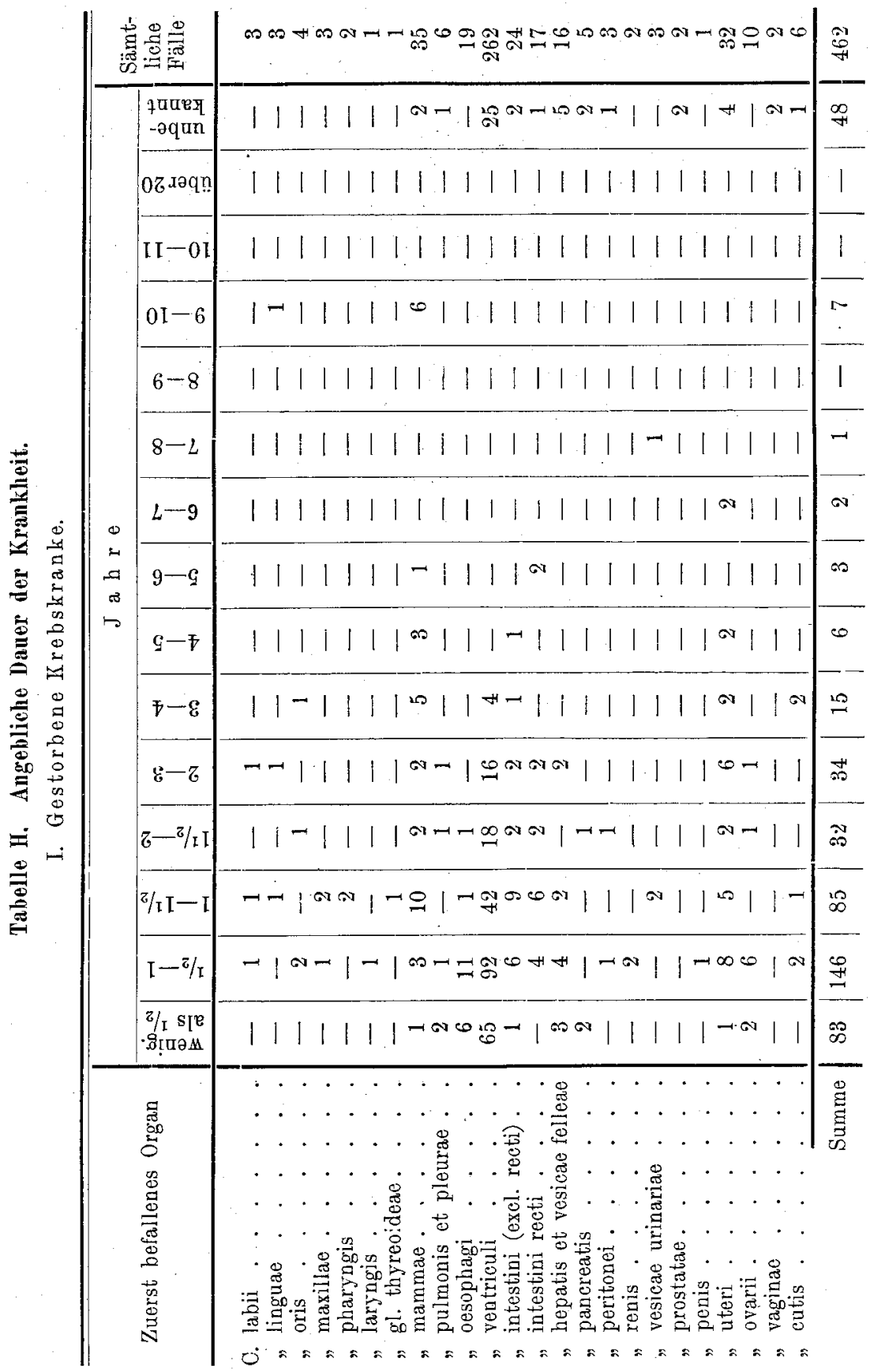


Sammelforschung über die Krebskrankheit in Schweden.

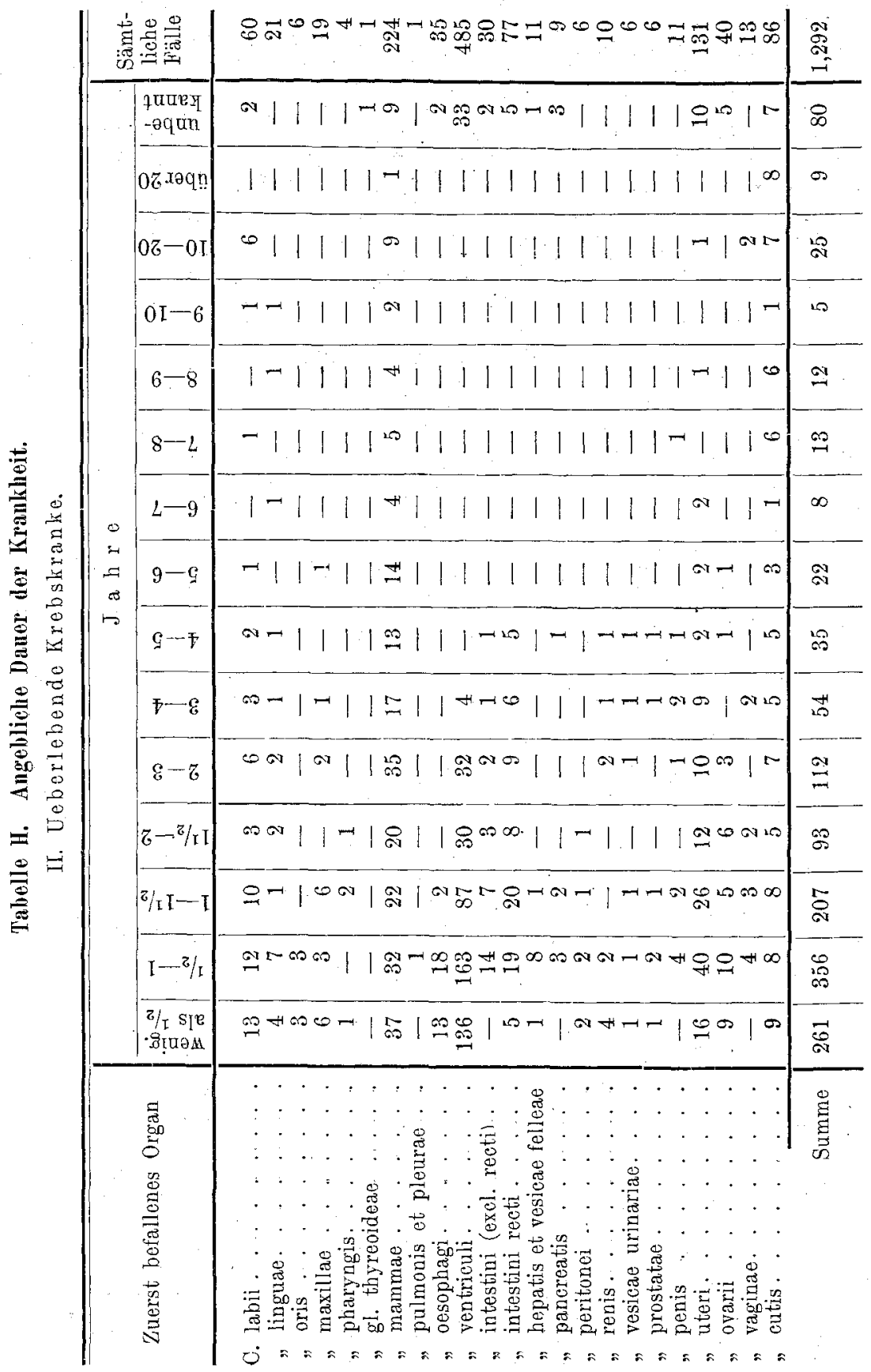


Sammelforschung über die Krebslrankheit in Schweden.

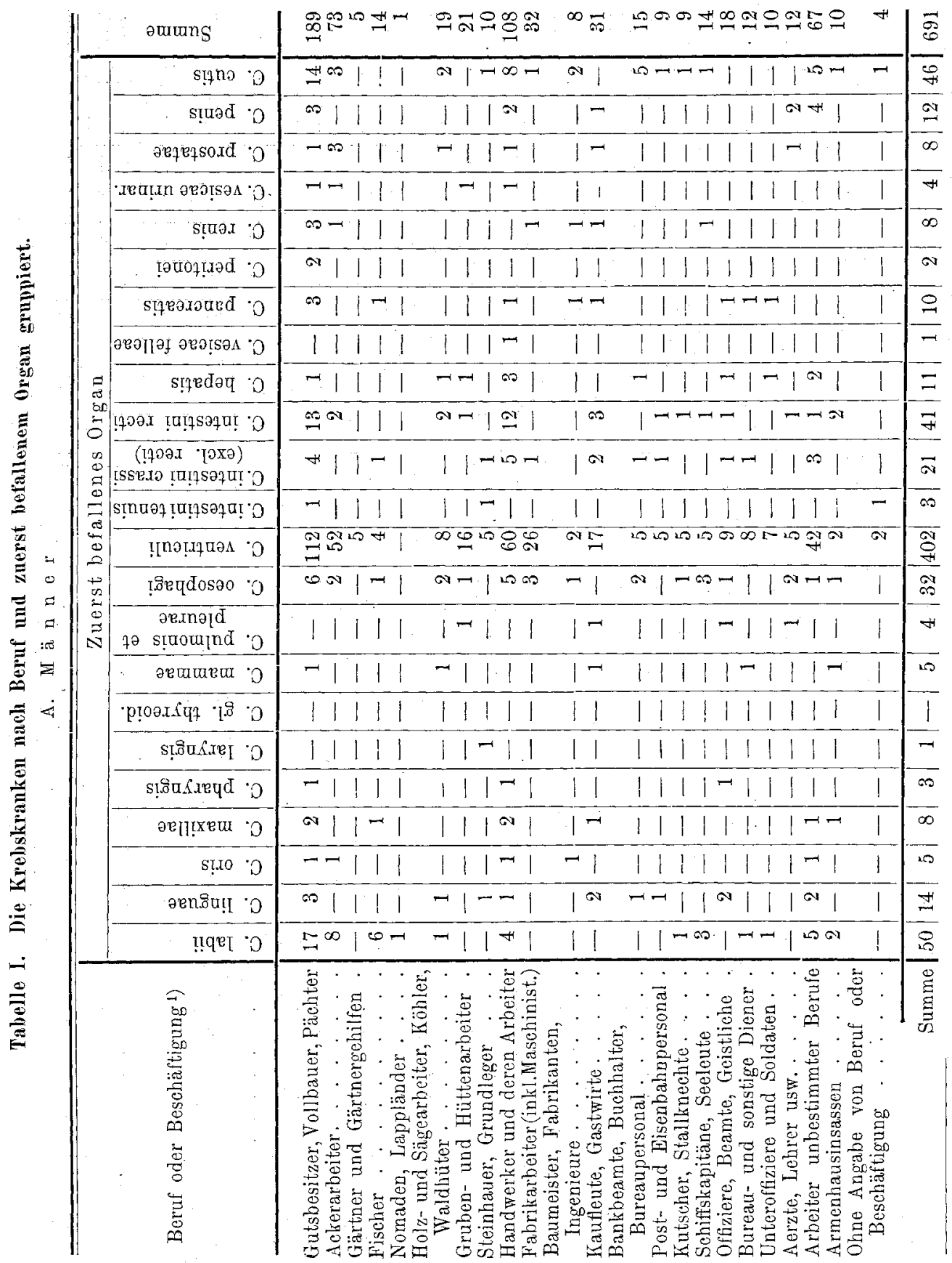


Sammelforschung über die Krebskrankheit in Schweden.

\begin{tabular}{|c|c|c|c|c|c|c|c|c|c|c|}
\hline & & əurwns & $\operatorname{lig}_{0} 0019$ & $\infty$ & 909 & 8.0 & 200 & 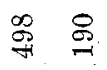 & $\stackrel{\theta}{2}$ & 2 \\
\hline & & $\operatorname{stqno} \cdot 0$ & $\infty 101$ & - & $1-\infty$ & 11 & 11 & $\mathscr{1}$ & $\infty$ & -1 \\
\hline & & 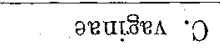 & $11-1$ & o & 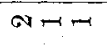 & 11 & 11 & 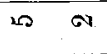 & 1 & 11 \\
\hline & & $\lfloor+1010$ & $\infty-\infty-$ & a & $\left.1\right|^{100}$ & $\infty n-$ & $\infty 1$ & \& & 1 & $\infty 1$ \\
\hline & & txәұn & बजान & - & $\operatorname{Nm}$ & मन & $\cos =$ & $\Leftrightarrow \stackrel{-}{1}$ & 90 & $0 \pi$ \\
\hline & & 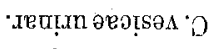 & 1111 & 1 & 111 & $1 \cdot 1$ & 11 & $\neg \quad \infty$ & 1 & 1 \\
\hline & & s!̣๐.x & 1111 & 1 & $1-1$ & 11 & 11 & $r \quad r$ & 1 & \\
\hline & & 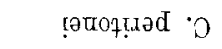 & 1111 & I & 111 & 1.11 & $\rightarrow 1$ & ar ar & - & 11 \\
\hline & & st7earaned $\cdot 0$ & -111 & 1 & $|\infty|$ & 111 & 11 & $\neg \quad 1$ & $\mid$ & | | \\
\hline & & 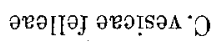 & 1111 & 1 & -11 & $1 \quad 11$ & 11 & $+r$ & 1 & $1 \mid$ \\
\hline & $\stackrel{30}{=}$ & sप̣edəu 0 & 1111 & 1 & 111 & 1.1 & 11 & $r$ or & | & \\
\hline & $\infty$ & 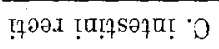 & $\infty 111$ & $\infty$ & $11^{20}$ & 1.11 & -1 & $\stackrel{9}{9}$ & 1 & \\
\hline & $\begin{array}{c}0 \\
0 \\
-1\end{array}$ & 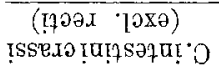 & $\infty \mid-1$ & - & $11 \infty$ & 111 & 11 & $\infty 0$ & | & \\
\hline$\approx$ & $\underset{\pi}{\pi}$ & 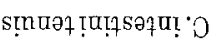 & -111 & 1 & $11 !$ & $1-1$ & 11 & $\infty 1$ & - & -1 \\
\hline $\begin{array}{l}0 \\
=\end{array}$ & 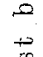 & 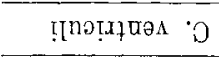 & 0201010 & $\Phi$ & 10000 & $\pi \infty 1$ & 10 & $\infty$ & 2 & $\cong$ \\
\hline i & 3 & !.ôeपุdosวo 0 & $11-\pi$ & 60 & $\rightarrow \mid \sigma$ & 11 & 11 & 20 & 1 & -1 \\
\hline Ex & $\infty$ & $\begin{array}{ll}\text { ar.matd } \\
\text { qa } & \text { sLuomind } \cdot O\end{array}$ & 1111 & l & 111 & 11 & ! & - & l & 1 \\
\hline$\overline{5}$ & & әеuureu 0 & $n- \pm N$ & {$[-$} & $1 \infty \infty$ & $\infty \infty$ & \pm- & $\stackrel{ \pm}{\Xi}$ & 10 & $\underset{-1}{\infty}$ \\
\hline & & 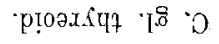 & 1111 & I & 111 & 111 & 11 & $-1 \quad-$ & 1 & 11 \\
\hline & & 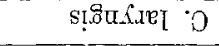 & 1111 & I & 111. & $|\cdot|$ & 11 & 1 & 1 & 11 \\
\hline & & st.ôt Arred $D$ & 1111 & 1 & 111 & 11 & $1 \mid$ & $\infty$ & 1 & 11 \\
\hline & & әRIIIXeur $\rho$ & $-1 \mid 1$ & 1 & $11-$ & $1-1$ & 17 & $20 \pi$ & 1 & -11 \\
\hline & & $\$ ! . .10 \circ$ & 1111 & 1 & 111 & | 1 & 11 & $\infty$ & 1 & 11 \\
\hline & & วยทดิu!̣ $D$ & $-11=$ & 1 & -10 & 11 & 11 & 100 & 1 & 11 \\
\hline & & IIqe & $\mid 1-1$ & 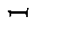 & $1 \mid-1$ & $1 \cdot 1$ & 11 & 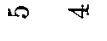 & 1 & $1-1$ \\
\hline & & 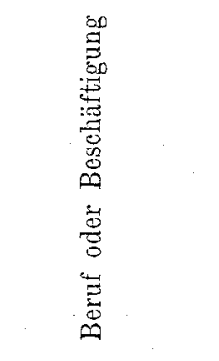 & 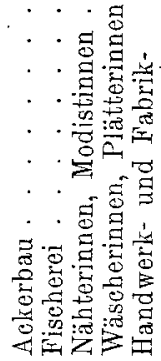 & 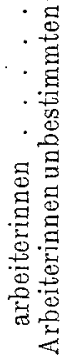 & 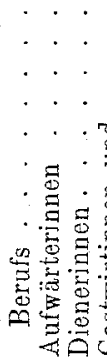 & 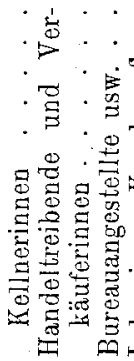 & 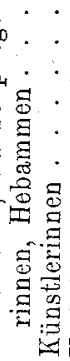 & 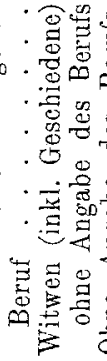 & 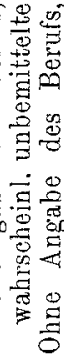 & 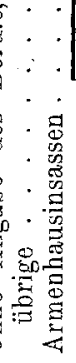 \\
\hline
\end{tabular}


diesen Zahlen und der Anzahl der Männer über 25 Jahre in den entsprechenden Berufsarten laut der letzten Volkszählung ${ }^{1}$ ), rund resp. 357000 und 840000 , würde nachstehende Krebsfrequenz, auf 100000 Einwohner berechnet, ergeben: für die erste Gruppe $76 \mathrm{Fälle,} \mathrm{für} \mathrm{die} \mathrm{zweite} \mathrm{50.} \mathrm{Ein}$ entsprechender Vergleich in bezug auf die Weiber lässt sich nicht durchführen, da die Frageblätter meistens keine Angaben über ihre soziale Stellung enthalten. Obgleich selbstverständlich kein höheres Mass von Genauigkeit obigen Ziffern beigemessen werden kann, erscheint jedoch der Unterschied der gefundenen Frequenz in den höheren und den niedrigeren Gesellschaftsklassen zu gross, um von Zufälligkeiten bedingt zu sein. Ein Umstand, der von einigem Einfluss gewesen sein könnte, ist der, dass die Männer aus den höheren Gesellschaftsklassen öfter ärztliche Hilfe suchen. Aber auch unter Berücksichtigung dieses Umstandes scheint jedenfalls das vorliegende Material dafür zu sprechen, dass der Krebs eine grössere Verbreitung unter den besser situierten als unter den schlechter situierten Gesellschaftsklassen hat.

\section{Erbliche Belastung, Ansteckung, lokale Prozesse sowie sonstige Verhältnisse.}

Von sämtlichen ermittelten Krebsfällen wurde in 343 Fällen erbliche Belastung angegeben, also in $19,6 \mathrm{pCt}$. Von diesen Fällen sind 113 $(16,35$ pCt.) männlichen, 230 (21,63 pCt.) weiblichen Geschlechts.

Die grössten Krebsgruppen betreffend, ergibt Tabelle $\mathrm{K}$, dass erbliche Belastung vorgekommen ist

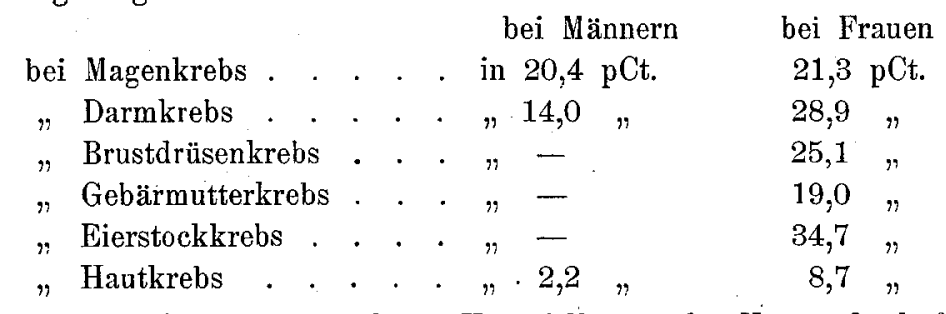

Diejenigen Fälle, wo mehrere Krebsfälle in der Verwandtschaft ermittelt wurden, finden sich im Folgenden ausführlicher angegeben.

1. Fälle von Magenkrebs.

1. Magenkrebs bei Vater, 1 Bruder und 2 Schwestern.

2. Magenkrebs bei Mutter und 1 Bruder.

1) Die in Frage stehende Volkszählung unterscheidet in jedem Beruf zwischen Männern über und unter 25 Jahren. Da fast alle männlichen Krebskranken, über welche Angaben eingelaufen sind, über 25 Jahre alt sind, dürfte ein derartiger Vergleich nicht unberechtigt sein. 
Tabelle K. Fälle, wo Krebskrankheiten in der Verwandtschaft des Kranken angegeben wurden.

A. Männer.

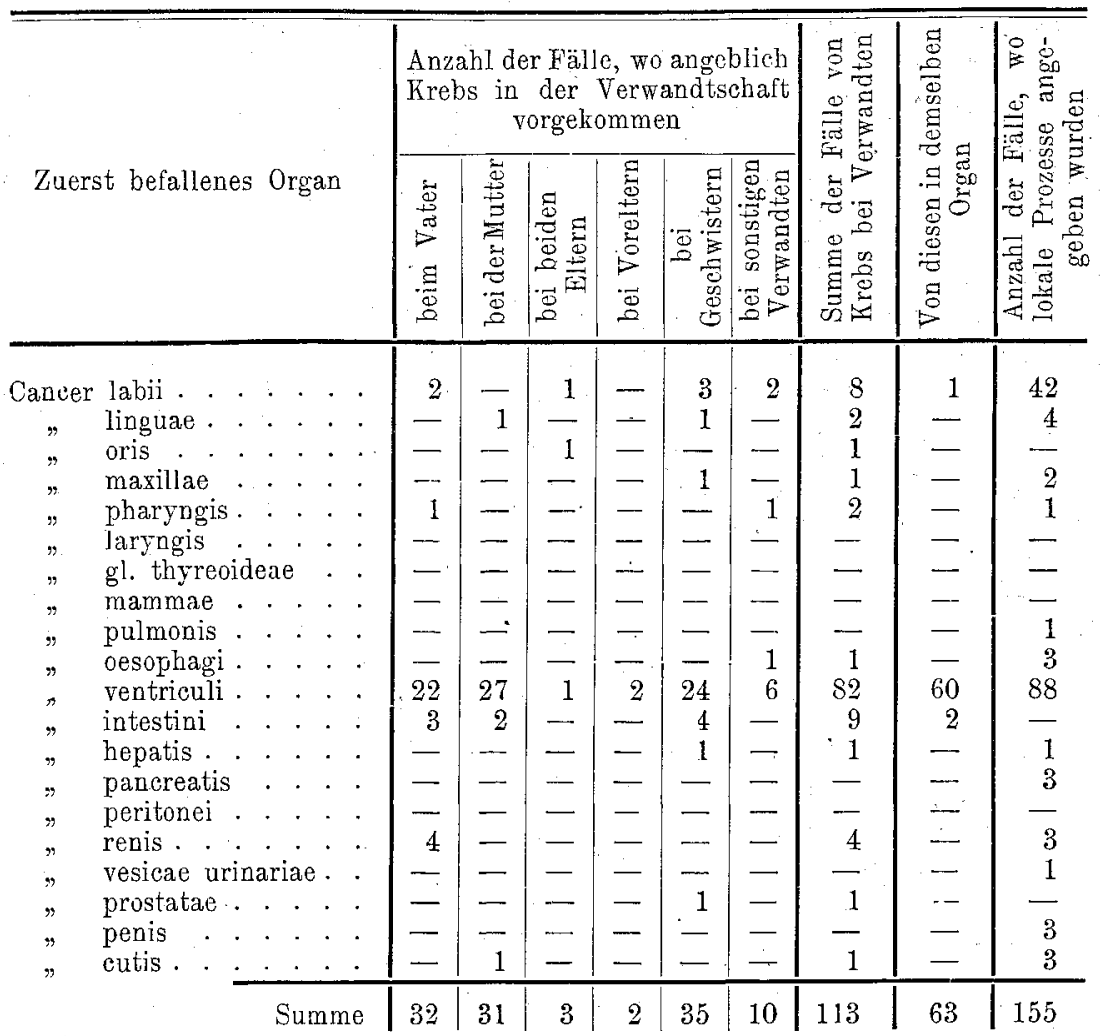

3. Magenkrebs bei 2 Brüdern.

4. Magenkrebs bei 1 Bruder und 1 Tochter, Nierenkrebs bei 1 Bruder.

5. Krebs bei Mutter und deren Mutter, Brustdrüsenkrebs bei 1 Schwester.

6. Magenkrebs bei Vater und 1 Bruder.

7. Krebs bei 2 Schwestern, Brustdrüsenkrebs bei 1 Schwestertochter und Magenkrebs bei 1 Schwestertochter.

8. Speiseröhrenkrebs bei Mutter, Magenkrebs bei 1 Schwester.

9. Magenkrebs bei 2 Schwestern.

10. Magenkrebs bei Mutter und 1 Schwester.

11. Brustdrüsenkrebs bei Mutter und deren Mutter, Zungenkrebs bei 1 Bruder.

12. Magenkrebs bei Mutter und 2 Schwestern. 
Tabelle K. Fälle, wo Krebskrankheiten in der Vcrwandtschaft des Kranken angegeben wurden.

B. Frauen.

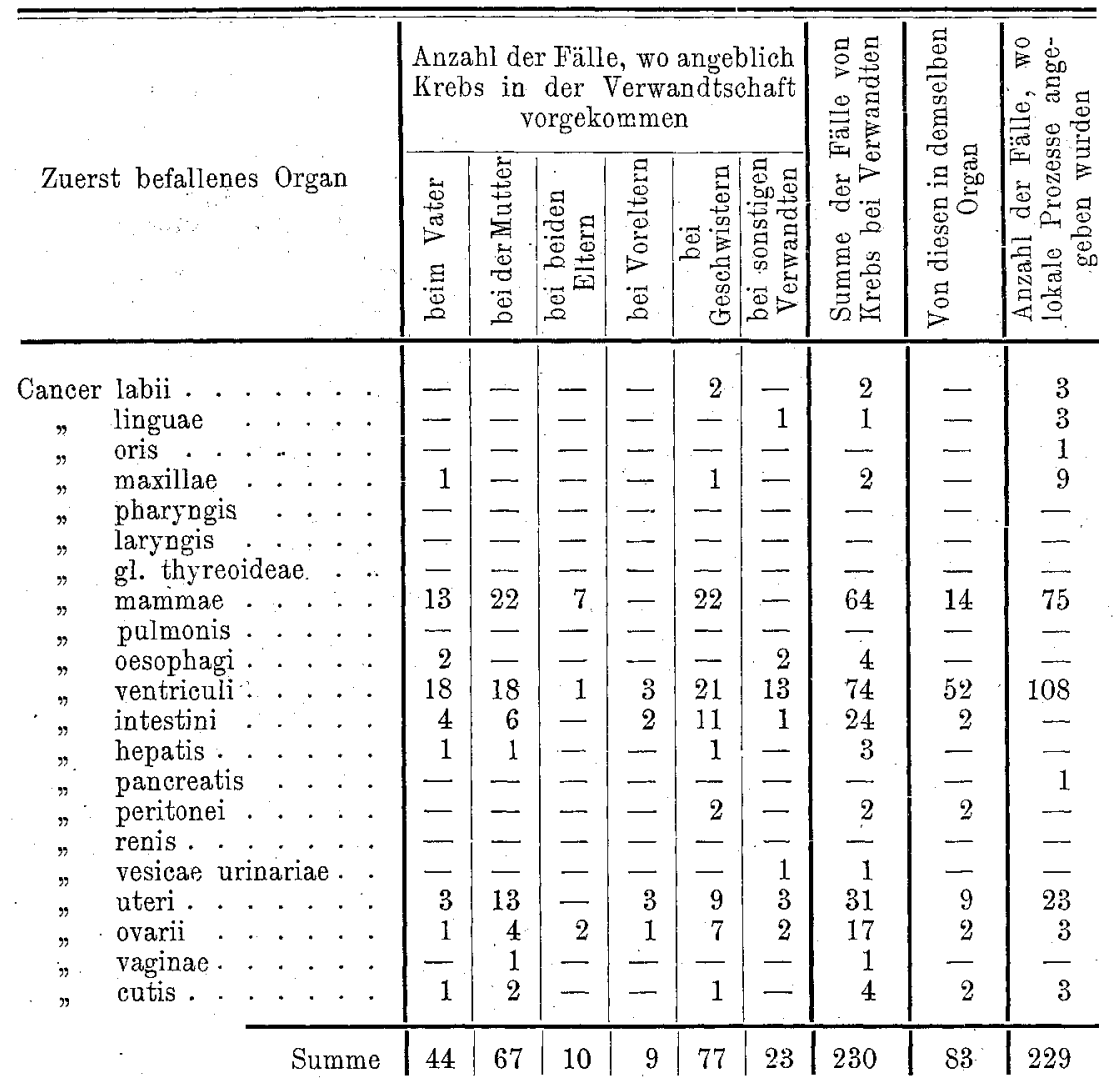

13. Krebs bei Vater, Mutter des Vaters, 2 Brüdern des Vaters, 1 Schwester des Vaters.

14. Magenkrebs bei Vater und 1 Schwester.

15. Magenkrebs bei Vater und Mutter.

16. Mundkrebs bei 1 Schwester, Magenkrebs bei 1 Bruder.

17. Lippenkrebs bei Vater, Magenkrebs bei 1 Schwester des Vaters und 1 Schwester.

18. Magenkrebs bei 1 Bruder der Mutter, Darmkrebs bei 1 Bruder.

19. Magenkrebs bei 1 Bruder, Gebärmutterkrebs bei 1 Schwester des Vaters. 


\section{Fälle von Darmkrebs.}

1. Krebs bei Vater des Vaters und 1 Bruder.

2. Magenkrebs bei Vater, Gebärmatterkrebs bei Mutter.

3. Krebs bei 1 Schwester und 1 Bruder der Mutter.

4. Magenkrebs bei 1 Bruder, Brustdrüsenkrebs bei 1 Schwester, Gesichtskrebs bei Mutter.

5. Magenkrebs bei Mutter und 1 Schwester.

6. Magenkrebs bei 1 Schwester der Mutter, Brustdrüsenkrebs bei 1 Schwester der Mutter.

7. Magenkrebs bei 1 Bruder und 1 Schwester.

8. Magenkrebs bei 1 Bruder, Bauchkrebs bei 1 Schwester.

9. Gesichtskrebs bei Mutter, Magenkrebs bei 1 Schwester.

\section{Fälle von Lippenkrebs.}

1. Wangenkrebs bei Vater, Halskrebs bei Mutter des Vaters, Gesichtskrebs bei 1 Cousine, Magenkrebs bei 1 Cousine der Mutter.

2. Magenkrebs bei Vater und Mutter, Krebs bei 1 Bruder des Vaters und 2 Schwestern des Vaters.

3. Magenkrebs bei 1 Bruder und 1 Schwester.

\section{Fälle von Brustdrüsenkrebs.}

1. Krebs bei Vater, 1 Bruder des Vaters und 1 Bruder.

2. Gebärmutterkrebs bei Mutter, Magenkrebs bei 1 Schwester des Vaters.

3. Brustdrüsenkrebs bei Mutter und 2 Cousinen.

4. Krebs bei Vater, 1 Bruder des Vaters und 1 Bruder der Mutter.

5. Gebärmutterkrebs bei 1 Schwester der Mutter, Leberkrebs bei 1 Bruder.

6. Magenkrebs bei 2 Geschwistern. Vaters.

7. Gebärmutterkrebs bei Mutter, Leberkrebs bei 1 Schwester des

8. Brustdrüsenkrebs bei Mutter und 1 Scbwester, Bauchkrebs bei 1 Schwester.

9. Brustdrüsenkrebs bei 1 Schwester der Mutter und 1 Schwester des Vaters, Magenkrebs bei 1 Schwester der Mutter, Nierenkrebs bei 1 Bruder der Mutter.

10. Magenkrebs bei 1 Bruder der Mutter, Darmkrebs bei 1 Bruder der Mutter.

11. Krebs bei 2 Cousinen.

12. Brustdrüsenkrebs bei 1 Schwester, Eierstockkrebs bei 1 Schwester.

13. Krebs bei Vater, Mutter und 2 Schwestern. 
14. Gebärmutterkrebs bei Mutter und 1 Schwester.

15. Brustdrüsenkrebs bei 1 Schwester, Unterleibskrebs bei 1 Schwester.

5. Fälle von Gebärmutter- und Eierstockkrebs.

1. Krebs bei Mutter der Mutter, 1 Bruder der Mutter und 1 Schwester der Mutter.

2. Brustdrüsenkrebs bei Mutter der Mutter, 1 Schwester der Mutter und 1 Cousine, Zungenkrebs bei 1 Cousine.

3. Magenkrebs bei Vater, Gebärmutterkrebs bei Mutter und 1 Schwester.

Im ganzen wurden also 49 Fälle ermittelt, wo, ausser beim Patienten, 2 oder mehrere Fälle von Krebs in der Verwandtschaft vorgekommen waren.

Die Ansteckung betreffend, haben fast alle Aerzte, welche Fälle gemeldet, wo Ansteckung vorgelegen haben sollte, dies mit mehr oder weniger Zaudern getan. In 10 Fälien sollte der Krebs durch Pflege eines Krebskranken übermittelt worden sein, in 5 Fällen sollte die Krankheit durch Zusammenwohnen mit einem Krebskranken oder Bewohnung vol Räumlichkeiten,-die früher von an Krebs verstorbenen Personen bewohnt wurden, übermittelt worden sein. In 33 Fällen ist der Krebs angeblich bei beiden Ehegatten vorgekommen. Es ist selbstverständlich, dass bei einer so häufigen Krankheit wie dem Krebs immer eine gewisse Zabl von Fällen bei beiden Fhegatten zu erwarten sind. Nur in dem Falle, dass die Zahl der tatsächlich beobachteten Fälle die durch Probabilitätsberechnung bel'echnete Anzahl der Fälle erheblich übersteigt, ist man berechtigt, eine grössere Krebsfrequenz bei Ehegatten anzunehmen. Das vorliegende Material gestattet indessen eine derartige Berechnung nicht.

In bezug auf die Bedeutung von lokalen Prozessen, vorausgegaugenen Krankheiten und einigen anderen Umständen, ist das Ergebnis ein ganz geringes. Die nachfolgenden Angaben dürften indessen der Erwähnung wert sein.

Beim Hautkrebs finden sich in 5 Fällen Angaben ïber alte Unterschenkelgeschwüre, in 2 Fällen hochgradige Ichthyosis und in 1 Fall Lupus vulgaris als vorausgegangener lokaler Prozess. Von 63 Fällen von Lippen-. krebs sind 31 Raucher und 7 Tabakkauer gewesen; in bezug auf die vorliegenden 24 Fälle von Zungenkrebs finden sich Angaben über: Rauchen oder Tabakkauen in 9 Fällen, kariöse Zäbne in 3 Fällen, Probieren von Wein in 2, Psoriasis linguae in 2. Von 22 Fällen von Kieferkrebs finden sich Angaben über lokalen Reizungszustand in 7 Fällen, direktes Trauma in 3 und Tabakmissbrauch in 5 Fällen; von 16 Fällen von Mund- und Schlundkrebs wird Tabakmissbrauch in 7 Fällen angegeben. Beim Magenkrebs findet sich vorausgegangenes Magengeschwür notiert in 34 Fällen männlichen $(8,4$ pCt. $)$ und in 59 Fällen weiblichen Geschlechts $(14,2$ pCt.). 
Chronischer Magenkatarrh oder andere chronisehe Magenkrankheiten sind dem Magenkrebs vorausgegangen: bei Mammern in 42 Fallen, bei Frauen in 37 Fälen. Von 7 Fallen von Krebs der Gallenwege hat sich in 5 Fällen Gallenstein gefunden, unter diesen bei 4 Frauen; von 10 Fallen von Pankreaskrebs bei Männern ist Gallenstein in 3 Falleu vorgekommen.

In bezug auf den Brustdrüsenkrebs finden sich notiert: zahlreiche Laktationen in 38 Fällen ( $15 \mathrm{pCt}$.), akute oder chronische Mastitis in 17. Fällen und Trauma in 18 Fälen. Beim Krebs der weiblichen Geschlechtsorgane findet sich notiert: in 41 Fallen $(25 \mathrm{pCt}$ ) zahlreiche Entbindungen (5 und mebr) und in 21 Fallen (12,8 pCt.) chronische Endometritis. Unter 12 Fällen von Peniskrebs findet sich angegeben, dass in 3 Fallen vorausgegangene lokale Prozesse von Bedentung gewesen sind.

Alkoholmissbrauch ist in 119 Fällen vorgekommen und findet sich erwähnt vorzugsweise bei Krebs der Leber, der Speiseröhre, des Magens und des Darms, nämlich mit 60 pCt., 31,2 pCt., 17,9 pCt. sowie 17 pCt. von sämtlichen Fällen von Krebs der resp. Organe.

Was Familienkrankheiten betrifft, hat das Material so kleine Ziffern ergeben, dass sie kaum der Erwähnung wert sind.

Die jetzt beendete Sammelforschung gibt uns - wie aus obigem Bericht hervorgeht - eine nicht zu unterschätzende. Kenntnis von der Frequenz und Ausbreitung des Krebses in unserem Lande, sein Vorkommen in verschiedenen Altern, bei Männern und bei Frauen, seine verschiedene Lokalisation usw. Jedoch sind die Zahlen, welche diese erste Sammelforschung ergeben hat, nicht gross genug, um irgendwelche sichere Schlussfolgerungen in betreff der genannten Verhältnisse zu gestatten. Nur durch fortgesetzte Sammelforschung - vielleicht nach teilweise geändertem Plane - kann das Material die hierfür erforderliche Grösse, erreichen. So viel ist jedoch sicher, dass der Krebs in unserem Lande eine erbebliche Verbreitung Lat. Selbstverständlich ist es von grösster Bedeutung, dass die Kranken in geeignete Pflege kommen, was am besten in eigens zu diesem Zweck errichtete Pflegeanstalten geschieht.

\section{Fäle von Sarkom.}

Um neben der Krebssammelforschung einen Einblick in die Frequenz des Sarkoms zu gewinnen, hatte das Komitee die betreffenden Aerzte ersucht, auch über die während der Sammelforschungszeit vorkommenden Fälle von Sarkom Mitteilung zu machen.

In den nacbstehenden Tabellen findet sich eine Uebersicht über die ermittelten Sarkomfälle. 
Sammelforschung über die Krebskrankheit in Schweden.

Die Sarkomfälle nach Alter, Geschlecht und Lokalisation gruppiert.

\begin{tabular}{|c|c|c|c|c|c|c|c|c|}
\hline A 1 te $r$ & 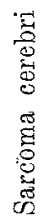 & 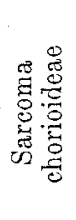 & 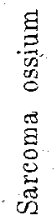 & 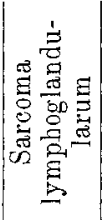 & 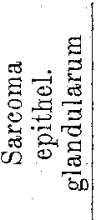 & 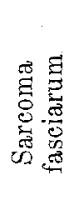 & 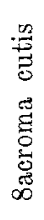 & : $\underset{\Xi}{\stackrel{g}{g}}$ \\
\hline
\end{tabular}

A. $M \ddot{a} n \mathrm{n}$ e $\mathrm{r}$

\begin{tabular}{|c|c|c|c|c|c|c|c|c|c|c|}
\hline $0-5$. & ahre & . . & - & - & - & - & - & 1 & 1 & 2 \\
\hline $5-10$ &, & . . . . & - & - & - & 1 & - & 1 & - & 2 \\
\hline $10-15$ & 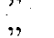 & . . . . & - & - & - & - & - & - & - & - \\
\hline $15-20$ & $"$ & . . & - & - & 2 & 1 & - & - & - & 3 \\
\hline $20-25$ & " & . & 2 & - & 1 & - & - & - & - & 3 \\
\hline $25-30$ &, & . & - & - & 1 & 1 & - & - & - & 2 \\
\hline $30-35$ & $n$ & . . . . & - & - & 3 & - & - & 2 & - & 5 \\
\hline $35-40$ &, & . . . & $\ldots$ & - & 1 & - & 1 & - & - & 2 \\
\hline $40-45$ & , & $\therefore$ & - & - & 2 & 1 & 2 & - & - & 5 \\
\hline $45-50$ & $"$ & . & 一 & - & 4 & 1 & 1 & - & - & 6 \\
\hline $50-55$ & $"$ & . & 一 & 一 & 4 & - & - & 1 & 1 & 6 \\
\hline $55-60$ & $"$ & . & - & - & 1 & 1 & 1 & - & 1 & 4 \\
\hline $60-65$ & $"$ & . & - & 1 & 3 & 1 & 2 & 1 & 1 & 9 \\
\hline $65-70$ &. & . & 一 & $\because$ & 1 & 2 & 1 & 2 & - & 6 \\
\hline $70-75$ &. & . . . & - & - & 2 & 2 & 一 & - & - & 4 \\
\hline $75-80$ & " & . . . . & $\ldots$ & $\cdots$ & -. & - & 1 & - & - & 1 \\
\hline $80-85$ & 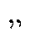 & . & 一 & - & 1 & - & 一. & - & 1 & 2 \\
\hline $85-90$ & , & . & - & - & 1 & 一 & $\cdots$ & - & - & 1 \\
\hline über 90 & $\because$ & . . . & 一 & - & 一 & 一 & 一 & - & 1 & 1 \\
\hline & & Summe & 2 & 1 & 27 & 11 & 9 & 8 & 6 & 64 \\
\hline
\end{tabular}

B. F r a $u$ e $\mathrm{n}$

\begin{tabular}{|c|c|c|c|c|c|c|c|c|c|c|}
\hline & & & & & & & & & & \\
\hline $0-5$ & ahre & . . & - & - & t & - & - & - & 1 & 2 \\
\hline $5-10$ & $"$ & . . & - & - & 一 & -- & - & 一 & - & 一 \\
\hline $10-15$ & , &.$\quad$. & - & - & - & - & - & - & - & - \\
\hline $15-20$ & , &.$\quad$. & -- & - & 2 & 1 & - & - & $\ldots$ & 3 \\
\hline $20-25$ &, &.$\quad$. & - & - & 2 & - & - & - & - & 2 \\
\hline $25-30$ & . &.. & - & - & - & - & 3 & - & - & 3 \\
\hline $30-35$ & $"$ & . & - & - & 1 & -- & - & 1 & 1 & 3 \\
\hline $35-40$ & $"$ & . . . . & - & 1 & - & - & 1 & 1 & - & 3 \\
\hline $40-45$ & $"$ &... & - & $\ldots$ & 2 & 2 & - & 2 & - & 6 \\
\hline $45-50$ & $"$ &... & $\rightarrow$ & - & 3 & 1 & 3 & - & -- & 7 \\
\hline $50--55$ & $"$ & . . . . & - & - & 3 & - & - & - & 一 & 3 \\
\hline $55-60$ & ., & . & 1 & - & 1 & 2 & 2 & - & 3 & 9 \\
\hline $60-65$ & , & . & $\cdots$ & - & 1 & 2 & 2 & - & - & 5 \\
\hline $65-70$ & $"$ & . . . . . & - & - & - & 1 & - & 1 & 1 & 3 \\
\hline $70-75$ &, & ... & - & 一 & 2 & - & - & - & - & 2. \\
\hline $75-80$ & $"$ & . & - & 1 & - & 一 & 1 & - & - & 2 \\
\hline $80-85$ & $"$ &.. & - & - & - & - & 1 & - & - & 1 \\
\hline $85-90$ & " & . . & - & - & - & - & - & - & - & 9 \\
\hline über 90 & $"$ & 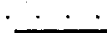 & 二 & - & - & $=$ & - & - & $=$ & 二 \\
\hline & & Summe & 1 & 2 & 18 & 9 & 13 & 5 & 6 & 54 \\
\hline
\end{tabular}


Die Sarkomfälle nach Geschlecht, Alter und Zivilstand gruppiert.

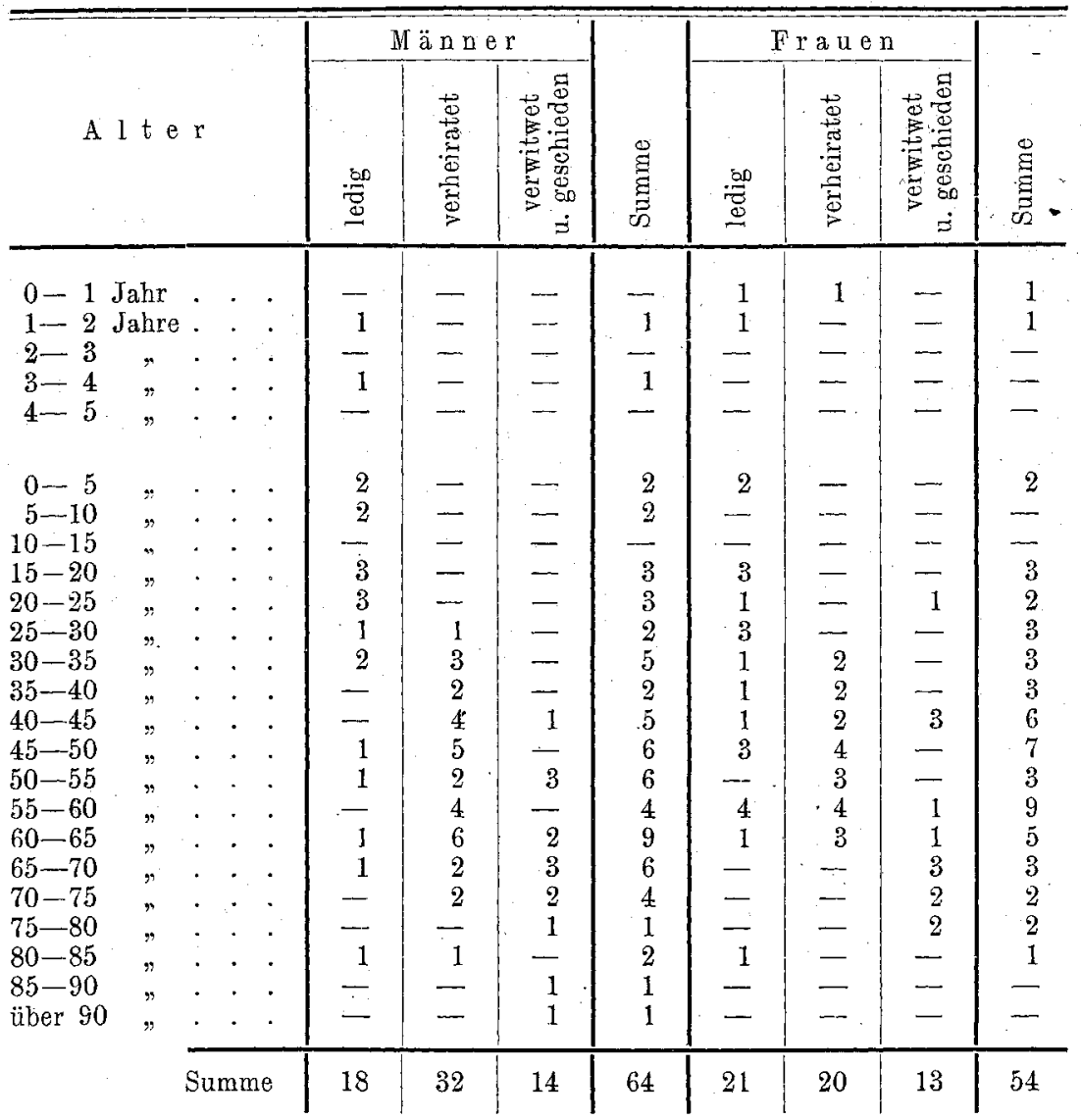

